\title{
Numerical Studies on a Severe Dust Storm in East Asia Using WRF-Chem
}

\author{
Xue Yu', Tijian Wang², Chong Liu' ${ }^{2}$, Lijie Pu${ }^{1}$ \\ ${ }^{1}$ School of Geographic and Oceanographic Sciences, Nanjing University, Nanjing, China \\ ${ }^{2}$ School of Atmospheric Science, Nanjing University, Nanjing, China \\ Email: tjwang@nju.edu.cn
}

How to cite this paper: $\mathrm{Yu}, \mathrm{X}$., Wang, T.J., Liu, C. and Pu, L.J. (2017) Numerical Studies on a Severe Dust Storm in East Asia Using WRF-Chem. Atmospheric and Climate Sciences, 7, 92-116.

http://dx.doi.org/10.4236/acs.2017.71008

Received: November 1, 2016

Accepted: January 16, 2017

Published: January 19, 2017

Copyright $\odot 2017$ by authors and Scientific Research Publishing Inc. This work is licensed under the Creative Commons Attribution International License (CC BY 4.0).

http://creativecommons.org/licenses/by/4.0/

(c) (i) Open Access

\begin{abstract}
Dust storm is one of the important natural disasters, which can have significant impact on terrestrial ecosystem, global climate, air quality and human health. In Mar. 19-23, 2010, a serious dust storm occurred over East Asia. It started from Mongolia, initially extending to the east, turning to the South of China, then back to the Northeast Asia. About $20 \%$ of the areas in China suffered from this severe dust event and the air was heavily polluted with massive airborne particulates. The Air Pollution Index (API) in many cities exceeded 500 when dust storm passed by, while the maximum surface $\mathrm{PM}_{10}$ concentration reached $1900 \mu \mathrm{g} / \mathrm{m}^{3}$ in east area. The coarse particles were dominated in $\mathrm{PM}_{10}$, with fine particles named as $\mathrm{PM}_{2.5}$ only accounting for $5 \%-20 \%$ at cities along the dust moving track in South and East China. MODIS and CALIPSO satellite data were used to investigate the horizontal and vertical patterns of optical parameters of dust aerosol. The average AOD reached $2-2.5$ on dust days in most southeast regions. The dust can be transported up to $5 \mathrm{Km}$ with maximum aerosol extinction coefficient of $0.35-0.4$ at $1-3 \mathrm{Km}$ in vertical. Synoptic weather was analyzed to understand the meteorological conditions and the backward trajectories were calculated to investigate the movements of air mass. The WRFChem model (Version 3.2) was applied to simulate the transport and deposition of the dust aerosols. The performance of Shaw (2008) and Chin (2002) parameterization schemes for dust emissions in WRF-Chem were evaluated. Modeling results were compared with the CUACE-Dust and RegCCMS. Investigations show that WRFChem has capability on simulations on dust emission, long range transport and deposition. Shaw (2008) scheme gives more reasonable spatial distribution of dust aerosols, while Chin (2002) scheme presents more better results in terms of $\mathrm{PM}_{10}$ surface concentration simulation. It is suggested that two schemes can be used at the same time in terms of simulation of dust pattern and concentration.
\end{abstract}

\section{Keywords}

Dust Storm, WRF-Chem, CUACE-Dust, RegCCMS, East Asia, AERONET, 


\section{Introduction}

East Asia has been a region with frequent dust storm which is considered to be a seasonal meteorological phenomenon. Usually, the dust originates in the deserts in Mongolia, China and Kazakhstan with high-speed surface winds. There are three key source regions of deserting China, which are Taklamakan in Xinjiang, Hunshandak in Inner Mongolia and the Loess Plateau. The intense dust storms can kick up dense clouds of fine, dry soil particles which can be carried eastward by prevailing winds and pass over China. As one of the severe disaster weather, dust storm always occurs in North China during the springtime. It can do harm to industrial and agricultural activities, transportation, climate change, atmospheric environment and human health [1] [2] [3] [4].

Many studies have been focused on dust storm in recent years. Especially, numerical models are widely applied to investigate the physical mechanism and long range transport of dust aerosols. Dust emission and transport studies have been undertaken since 1980s [5] [6] [7]. Gillette and Hanson (1989) combined atmospheric data with land surface data for wind erosion assessment to investigate the spatial and temporal variations of dust production in the United States [8]. Marticorena and Bergametti (1995), Shao et al. (1996) and Marticorena et al. (1997) have developed wind erosion schemes accounting for the impact of surface properties on sand drift and dust emission [9] [10] [11]. Shao et al. (1997) and Lu et al. (2001) have developed and implemented an almost fully integrated wind erosion modeling and prediction system [12] [13]. Alfaro and Gomes (2001) performed a modeling work on mineral aerosol production by wind erosion, focusing on emission intensities and aerosol size distributions in source areas [14]. Song et al. (2004) conducted a dust simulation and prediction in China during the spring of 2002 using numerical model [15]. Gong et al. (2008) reported an integrated sand and dust storm forecasting system CUACE-Dust (Chinese Unified Atmospheric Chemistry Environment for Dust) [16]. Based on the 1991-2010 simulation of dust aerosol emissions with the global climate model CAM5.1, Liu et al. (2015) analyzed the globally spatial and temporal variations of dust aerosol emissions over major deserts [17]. To ensure the accuracy of simulation, the parameterization scheme should be considered all of the uncertain factor: wind speed, surface properties. Gherboudj et al. (2015) showed that soil moisture and soil texture have significant roles in the dust emissions over the Middle East and North Africa [18]. However, few study has been conducted on dust storm simulation in China using the new generation weather research, forecast and chemistry model WRF-Chem. Wu et al. (2013) had clarified the uncertainty in dust budget over East Asia simulated by WRF-Chem with six different dust emission schemes [19]. By using WRF-Chem, Liu et al. (2016) gave the radiative forcing of dust aerosol and the radiative feedbacks on the planetary boundary layer in North China during a typical Asian dust storm [20].

In Mar., 2010, starting from Mongolia, a dust storm occurred with widely impacting area and heavy air pollution. This dust storm event has close relations with the air 
temperature increases and strong wind prevailing during the development of Mongolia cyclone. Since Spring of 2010, the air temperature increases gradually, the soil is unfrozen, the surface heating becomes fast, and resulting in strong instability in the whole atmosphere and strong wind with the intersection of warm and cold air, which provide dynamical conditions for the breakout of dust storm. In addition, the Mongolia cyclone is strongly developed and located near source regions of dust, leading to strong upward movement of the air which is beneficial for the occurrence of dust storm.

In this paper, the characteristics of the severe dust storm were investigated by both observational and numerical studies. The models and data are descripted in Section 2. Surface observation of $\mathrm{PM}_{10}$ concentration and aerosol optical parameters from AERONET (Aerosol Robotic Network) are analyzed. Satellite data from MODIS (Moderate Resolution Imaging Spectroradiometer) and CALIPSO (Cloud-Aerosol Lidar and Infrared Pathfinder Satellite Observations) are analyzed. Modeling studies were performed using WRF-Chem (Whether Research and Forecasting model with Chemistry) in consideration of two different dust schemes as proposed by Shaw (2008) and Chin (2002). The model results were compared with those from CUACE-Dust and RegCCMS, which are models developed by Chinese scientists and had been applied for dust simulation. These results are presented and discussed in Section 3. The final conclusions and future perspective are given in Section 4.

\section{Models and Data}

\subsection{Models}

\subsubsection{WRF-Chem}

WRF-Chem is a new generation model where the air quality component (Chem) and meteorological component (WRF) are fully coupled "online". The meteorological model WRF is a next-generation mesoscale numerical weather prediction system designed to serve both operational forecasting and atmospheric research needs. It is suitable for use in a broad spectrum of applications across scales ranging from meters to thousands of kilometers. The Chem model contains relatively comprehensive physical and chemical processes, includes convective, adjective and turbulent chemical transport, biogenic and anthropogenic emissions, deposition (dry and wet), photolysis, gas and aqueous chemical transformation, and aerosol chemistry and dynamics (including inorganic and organic aerosols) as well as the processes of aerosol direct and indirect effect through interaction with atmospheric radiation, photolysis, and microphysics.

In WRF-Chem version 3.2, two dust production schemes are implemented in the model so that it can be applied on dust simulations. Shaw (2008) used a dust generating module and the land cover data sets to describe how particles will be emitted with winds, which are included in the Dust Regional Atmospheric Model (DREAM) [21]. DREAM can be configured for multiple particle size bins. Chin (2002) adopted a new approach which has been used in the Georgia Institute of Technology-Goddard Global Ozone Chemistry Aerosol Radiation and Transport (GOCART) model to identify the dust source [22]. Dust particles ranging from 0.1 to $6 \mathrm{~mm}$ in radius are considered in the model. The emission flux is expressed as functions of a dimensional factor, proba- 
bility-source function, fraction of size group within the soil, 10-m wind speed, and the threshold velocity of wind erosion determined by particle size and surface wetness. For more detail, previous works from Shaw et al. (2008) and Chin et al. (2002) can be referred to.

\subsubsection{CUACE-Dust}

CUACE-Dust (Chinese Unified Atmospheric Chemistry Environment for Dust) is an integrated sand and dust storm forecasting system which consists of a comprehensive dust aerosol module with emission, dry/wet depositions and other atmospheric dynamic processes, and a data assimilation system using observational data from the CMA (China Meteorological Administration) ground dust monitoring network and retrieved dust information from a Chinese geostationary satellite-FY-2C (Gong et al., 2008; Niu et al., 2007) [16] [23]. CUACE-Dust has been an operational model for dust forecast. Here, the model is applied for comparison studies with WRF-Chem.

\subsubsection{RegCCMS}

RegCCMS is a Regional Climate and Chemistry Modeling System developed by Nanjing University. It was designed for studies on the climatic effect of different aerosols, including sulfate, nitrate, black carbon, organic carbon, sea salt as well as dust (Wang et al., 2009, 2010; Zhuang et al., 2010; Li et al., 2009) [24] [25] [26] [27]. The dust scheme applied in RegCCMS is referred to Marticorena and Bergametii (1995)'s work [9]. The coarse, fine and iken modes were treated in three bins. Heterogeneous reactions on dust particles were considered as described by Deng et al. (2011) [28]. The indirect effect of dust aerosols on regional climate over East Asia was investigated by Shen et al. (2011) on the base of RegCCMS [29].

\subsection{Observations/Measurements}

\subsubsection{Surface Data}

The Air Pollution Index (API) data as well as $\mathrm{PM}_{10}$ surface concentration data from 86 stations were collected to analyze the spatial distribution of air pollution and long range transport of dust aerosols during Mar. 17-24,2010. API is a number to describe daily air quality, which is calculated by the observed surface concentrations of three air pollutants $\left(\mathrm{SO}_{2}, \mathrm{NO}_{2}, \mathrm{PM}_{10}\right)$ based on Chinese Air Quality Standard. There are five grades for API. They are <50, $50-100,100-200,200-300$, and $>300$. API $<50$ and $50-100$ represents for the good and better air quality, while the API $>100$ means that the air is polluted in different levels. The API and daily averaged $\mathrm{PM}_{10}$ data is reported by Chinese Environment Monitoring Station (http://www.cnemc.cn).

AERONET data at three sites of Xianghe (Beijing), NUIST (Nanjing), and HokTsui (Hong Kong) were collected (in Figure 1), including aerosol optical depth (AOD) at $340,380,440,500,675,870,1020,1640 \mathrm{~nm}$. We use fine mode AOD at $500 \mathrm{~nm}$, coarse mode $\mathrm{AOD}$ at $500 \mathrm{~nm}$, fine mode fraction at $500 \mathrm{~nm}$ and angstrom parameter. The optical characteristics of dust aerosols can be revealed from the surface-based observations. All these data can be download at http://aeronet.gsfc.nasa.gov/new_web/data.html. It's worth noting that AERONET data represent the state of the overall atmospheric column. 


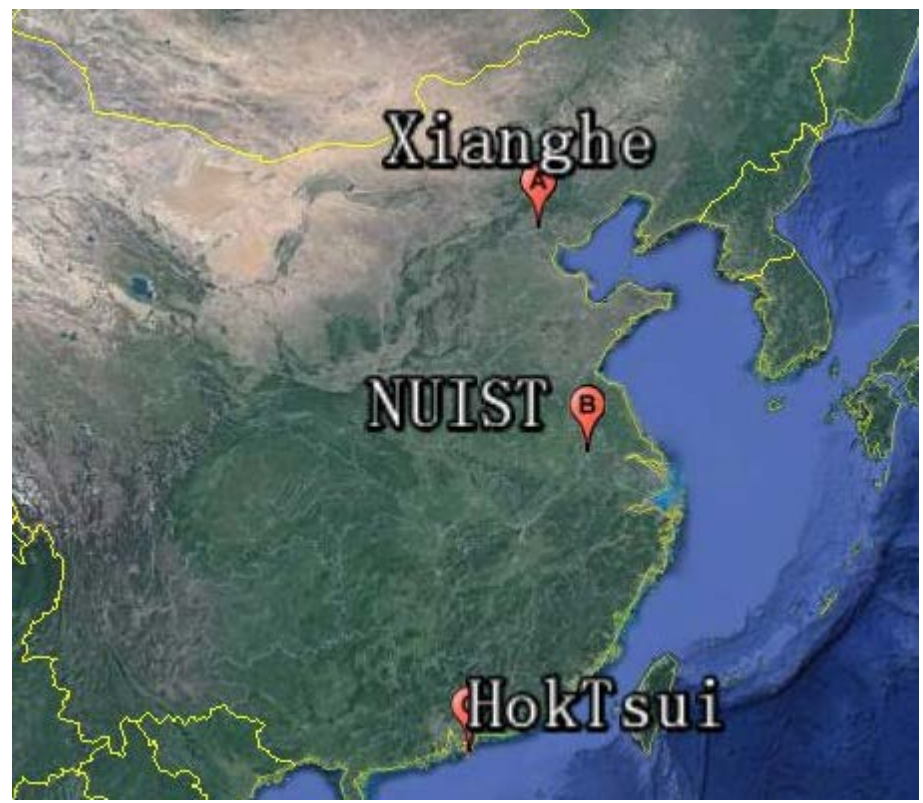

Figure 1. Three AERONET stations in China.

\subsubsection{Satellite Data}

MODIS AOD $(550 \mathrm{~nm})$ data were selected for investigation on geographical/spatial patterns of dust aerosol. Global daily Level 3 data are used from the Terra platform with the spatial resolution of $1 \times 1$ degree. Although the data only covers a few part of China in space and time, it does provide some useful information on how aerosols are transported during the different stage of dust storm. The data set can be download at http://disc.sci.gsfc.nasa.gov/giovanni/ and analyzed and visualized with the Giovanni online data system, developed and maintained by the NASA GES DISC(Acker et al., 2007) [30].

CALIPSO (Cloud-Aerosol Lidar and Infrared Pathfinder Satellite Observations) Lidar Level 2 Version 3.01 was collected for this study. It includes backscatter coefficients, depolarization ratio profile and extinction coefficients. Extinction coefficient was applied for investigation vertical optical characteristics of dust aerosol. CALIPSO data are provided by NASA Langley Research Center Atmospheric Science Data Center. Shun et al. (2016) give the statistical characteristics of aerosol extinction coefficient profile in East Asia from CALIPSO [31].

\section{Results and Discussions}

\subsection{Observations}

\subsubsection{API and $\mathrm{PM}_{10}$}

As affected by dust storm, the air was heavily contaminated with more particles. The API is an effective index to describe how the air is polluted. In China, API is divided into five levels (<50: excellent; 50 - 100: good; 100 - 150: slightly polluted; 150 - 200: low grade polluted; 200 - 250: medium grade polluted; 250 - 300: medium to heavily polluted; >300: heavily polluted). During Mar. 19-23, 2010, the severe dust storm occurred in China. Figure 2 shows the evolution of the API at 86 stations during the event. Dust started from west and south Mongolia in the afternoon of Mar. 18 as influenced by 


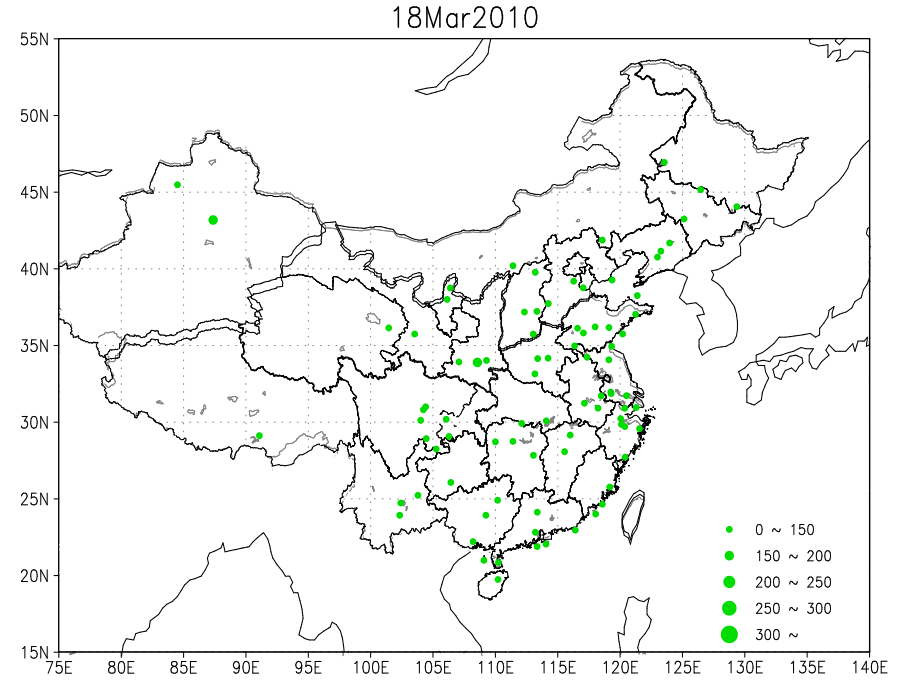

(a)

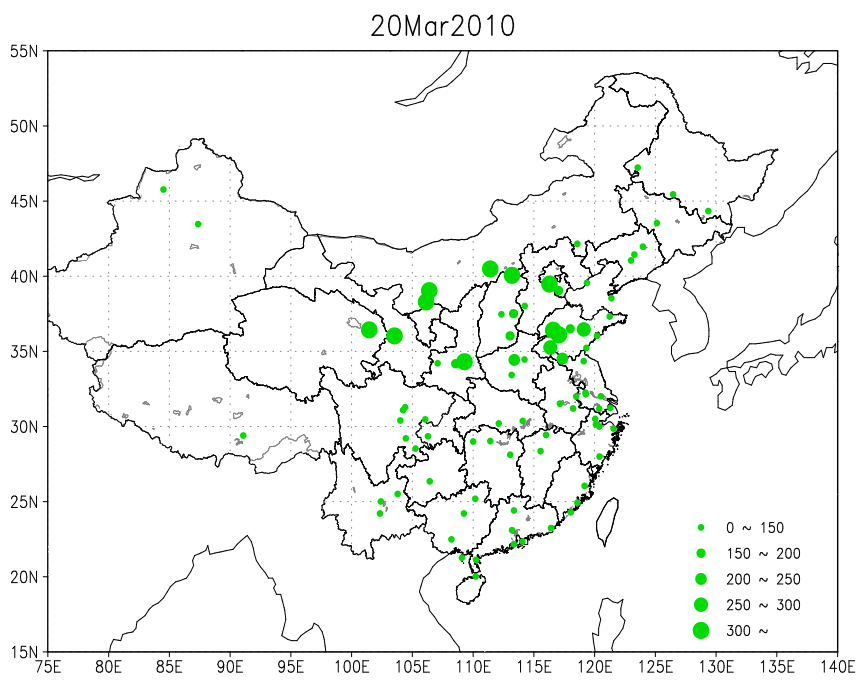

(c)

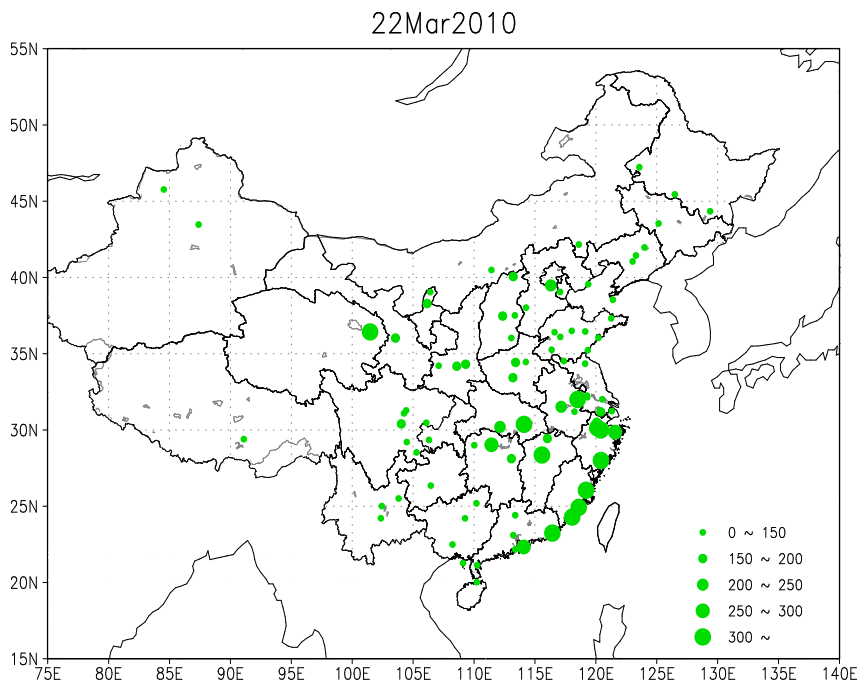

(e)

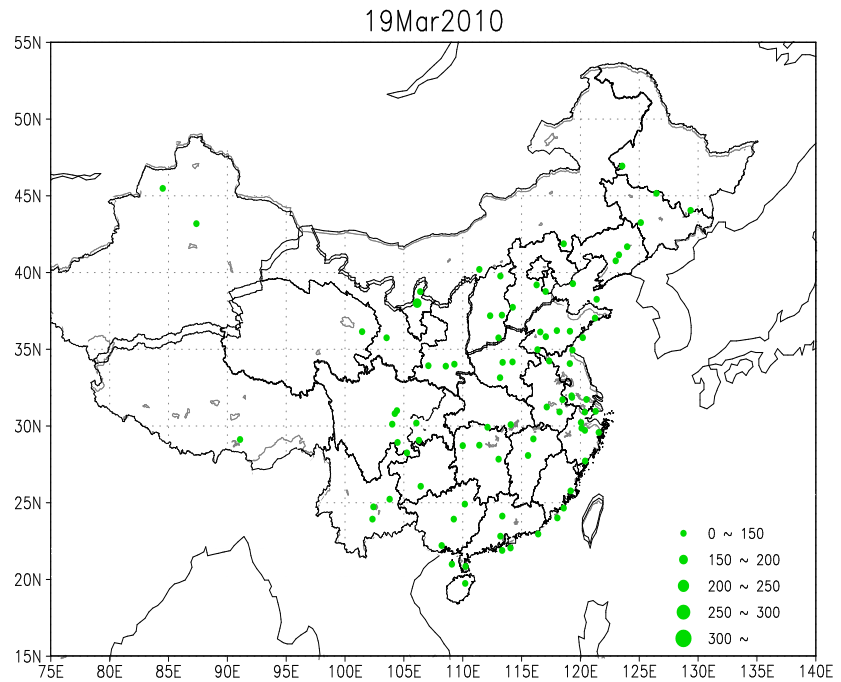

(b)

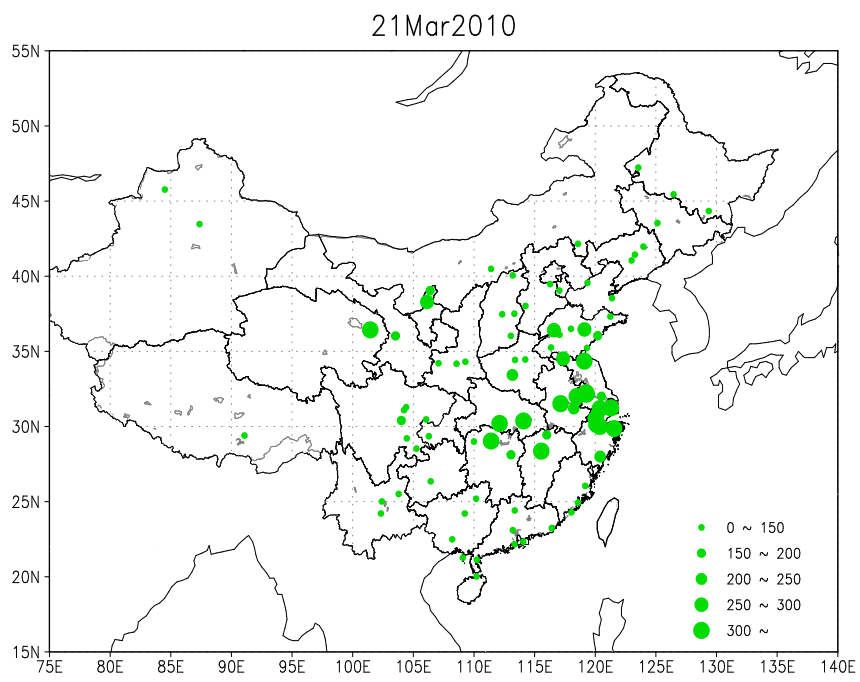

(d)

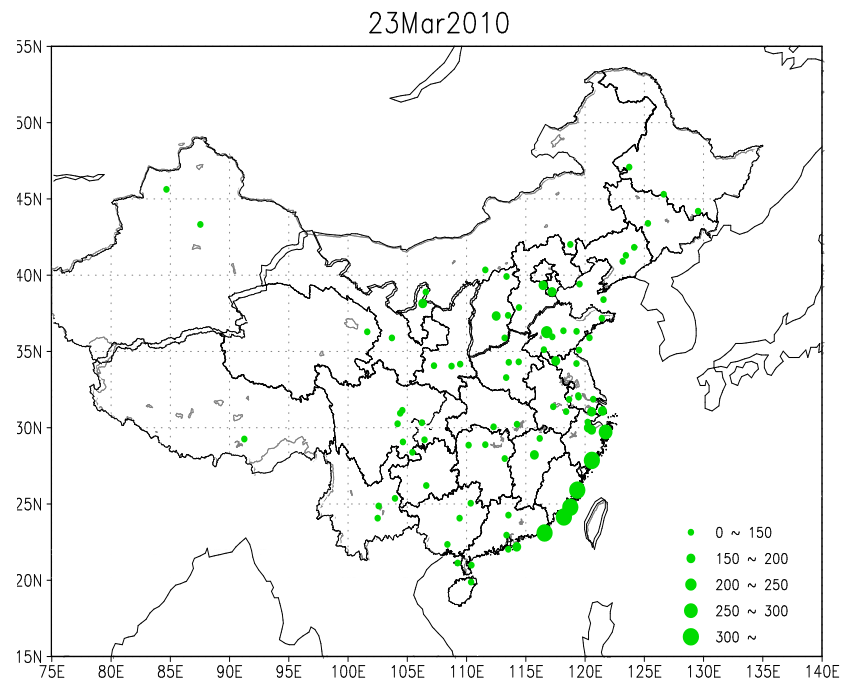

(f)

Figure 2. API at 86 stations during Mar. 18 - 23 (<50: excellent good; 50 - 100: good better; 100 - 150: slightly polluted; 150 - 200 : low grade polluted; 200 - 250: medium grade polluted; 250 - 300: medium to heavily polluted; $>300$ : heavily polluted). 
Mongolia cyclone and cold air. Dust storm hit China from Mar. 19. About 16 provinces or municipals, including Xinjiang, Inner Mongolia, Qinghai, Gansu, Ningxia, Shanxi, Shanxi, Hebei, Beijing, Tianjin, Shandong, Henan, Jiangsu, Anhui, Hubei, Sichuan, were suffered from this dust event on Mar. 20. API increase significantly and abruptly to 300 and exceeded 500 in many northern cities. The API maximum shifted to the southeast area, suggesting the transport of dust aerosols eastward and southward. The dust is transported from source regions to coastal areas, including Jiangsu, Zhejiang, Hubei, Anhui and Shanghai, on the day of Mar. 21. API remains high at North and East China with maximum of 500. In Mar. 22 and 23, dust aerosol continued to be transported to southeast China, far reaching Taiwan area. API of more than 500 in Zhejiang, Fujian and Guangdong provinces were observed. API higher than 400 in Hong Kong was recorded, which was never reported before. On Mar. 24, API at all stations decrease below 200, showing the weakness of dust transport in continental China. The spatial distribution of API during Mar. 18 - 23 show the spread of dust to southeast with heavy pollution induced. This dust event has confirmed to be the most widely-spread and intense one since 2009.

During the episode of dust storm, the primary pollutant in the air is inhalable particulate named as $\mathrm{PM}_{10}$. Figure 3 illustrates the daily average surface concentration of $\mathrm{PM}_{10}$ at 86 stations operated by China Environment Monitoring Center. Figure 3 shows that the maximum of surface hourly $\mathrm{PM}_{10}$ concentration for each site ranges from 500 to $2000 \mu \mathrm{g} / \mathrm{m}^{3} . \mathrm{PM}_{10}$ of $944 \mu \mathrm{g} / \mathrm{m}^{3}$ and $1990 \mu \mathrm{g} / \mathrm{m}^{3}$ in Shanghai and Nanjing were observed. Staring from the noon of Mar. 21, hourly $\mathrm{PM}_{10}$ concentration increased rapidly in Hong Kong with maximum of $783 \mu \mathrm{g} / \mathrm{m}^{3}$. The maximum hourly $\mathrm{PM}_{10}$ level of $1724 \mu \mathrm{g} / \mathrm{m}^{3}$ in Taiwan was also recorded. $\mathrm{PM}_{2.5} / \mathrm{PM}_{10}$ mass concentration ratio accounted for $14 \%$ and $3 \%$ in Shanghai and Nanjing, showing the domination of coarse particles affected by dust aerosols.

\subsubsection{Aerosol Optical Parameters}

The optical parameters observed at Xianghe, Beijing on Mar. 21 were illustrated in Figure 4. The dust storm hit Beijing from Mar. 20 and intensified on Mar. 21. High AOD (2.5) was measured with low fine mode fraction (0.2) and small angstrom parameter ( 0.5). According to Tanre et al. (2001), angstrom parameter ranges between -1 to 0.5 for dust aerosol [32]. In general condition, the urban air is polluted due to emissions from industry and transportation, which is characterized with high fine mode fraction and large angstrom parameter due to the domination of fine particles which induce much strong scattering. Angstrom parameter is between 1.1 to 2.4 for industrial aerosol (Dubovik et al., 2001) [33]. The observed low angstrom parameter suggested that coarse particles are dominated during the dust event.

Figure 5 depicts the optical parameters observed at HokTsui, Hong Kong. It shows that AOD remains high on Mar. 22. Coarse particle is dominated in total AOD, and fine mode fraction only account for $20 \%-40 \%$. AOD $(500 \mathrm{~nm})$ varied at a mean level of 0.8 and the peak can be more than 1. Most of the Spectral Deconvolution Algorithm (SDA) is below 1 Angstrom parameter $(440-870 \mathrm{~nm}$ ) is below 0.7 and as low as 0.2 , suggesting the weak scattering due to domination of coarse particles. The observed optical parameters confirmed that Hong Kong was hit by the dust storm, which has 


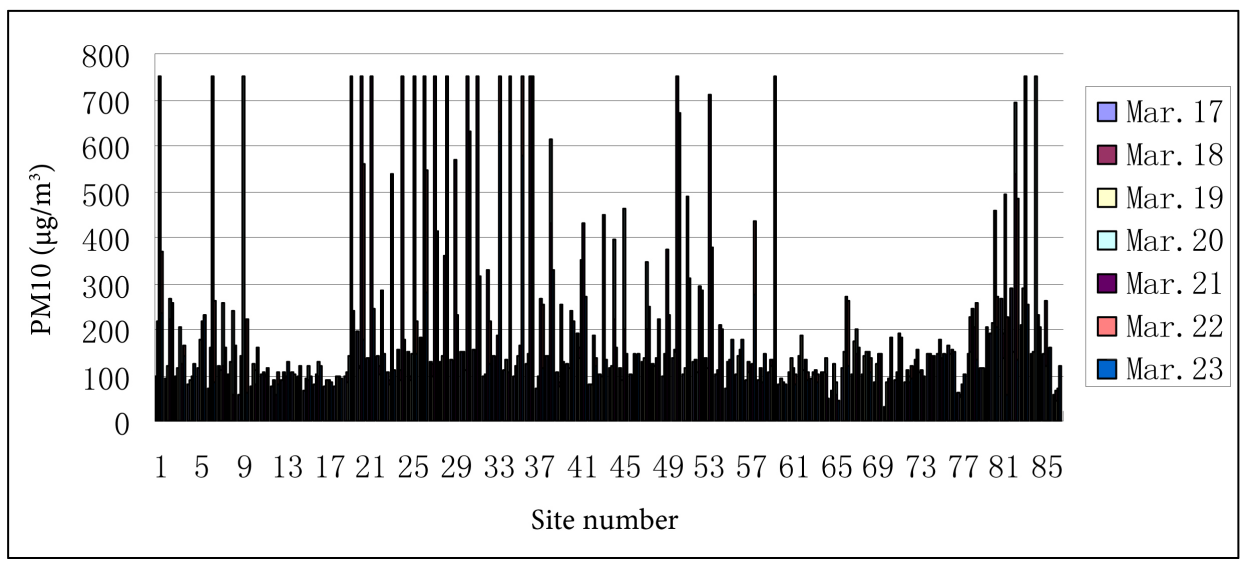

(a)

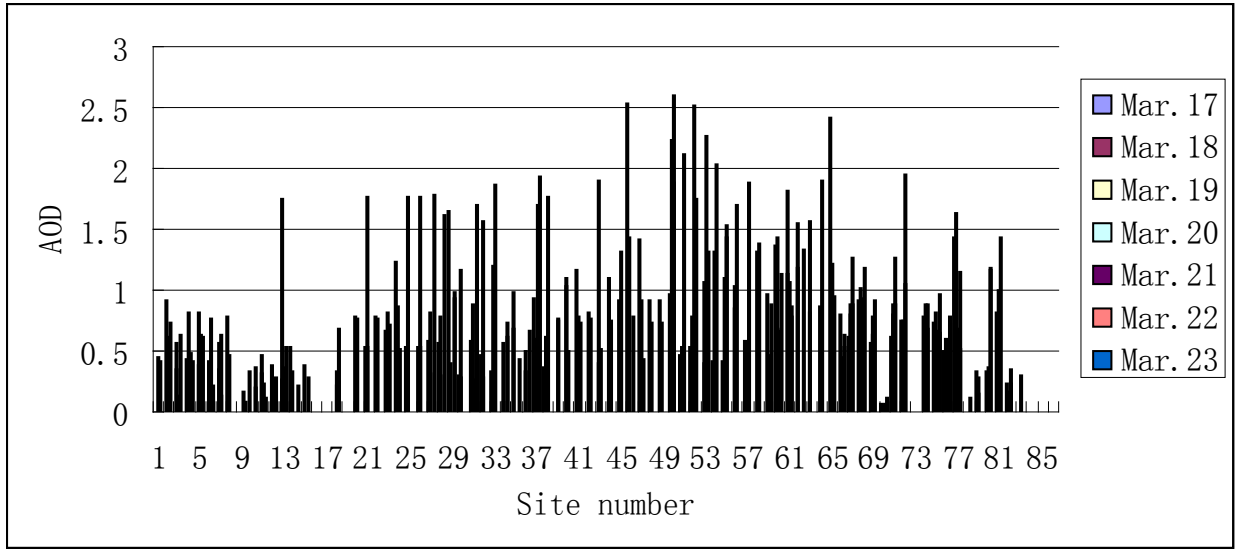

(b)

Figure 3. (a) $\mathrm{PM}_{10}$ surface concentration and (b) MODIS AOD at 86 cities.

never occurred before in the Hong Kong history.

\subsubsection{MODIS AOD Data}

The spatial/geographical distributions of AOD (550 nm) from MODIS during Mar. 1823 were presented in Figure 6. Although MODIS does not give retrieval AOD value in most area in northwest China, variation of AOD in east China can provide evidence of long range transport of dust form northwest to southeast. On Mar. 21, much high AOD was observed in central and southeast China, extending to East Ocean. Coverage area with high AOD decreases in the following two days. Considering mass concentration, the coarse particles contribute much in the total aerosols. However, both coarse and fine particles have large numbers during the dust days, resulting in strong aerosol extinction coefficient and large AOD with maximum of more than 2.5.

Figure 7 is the time series of AOD averaged over the region covering $70 \mathrm{E}-140 \mathrm{E}$, $10 \mathrm{~N}-60 \mathrm{~N}$. As expected, AOD shows gradual increase before Mar. 21, reaching 0.6 on the day of Mar. 21, and then decrease after Mar. 21. The aerosol small mode optical depth remains small and only accounts for $41 \%$ of total AOD, showing the dominance of coarse particles. The mass concentration ratio of $\mathrm{PM}_{2.5} / \mathrm{PM}_{10}$ in urban area is about $60 \%-70 \%$ in non dust days. Angstrom parameter also exhibits lower value of 1, suggesting that the contribution of coarse particle is significant. On Mar. 22, although 


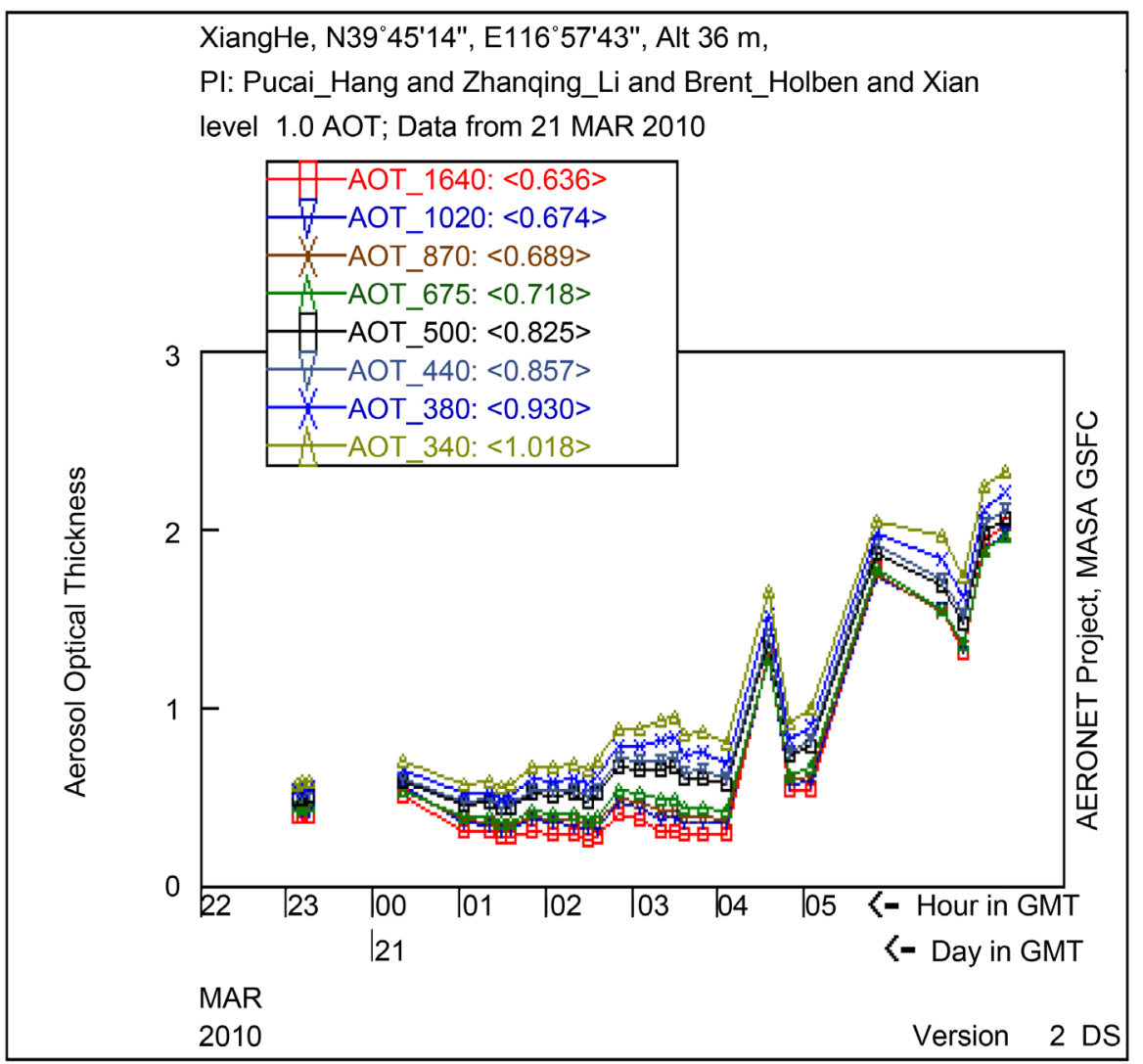

(a)

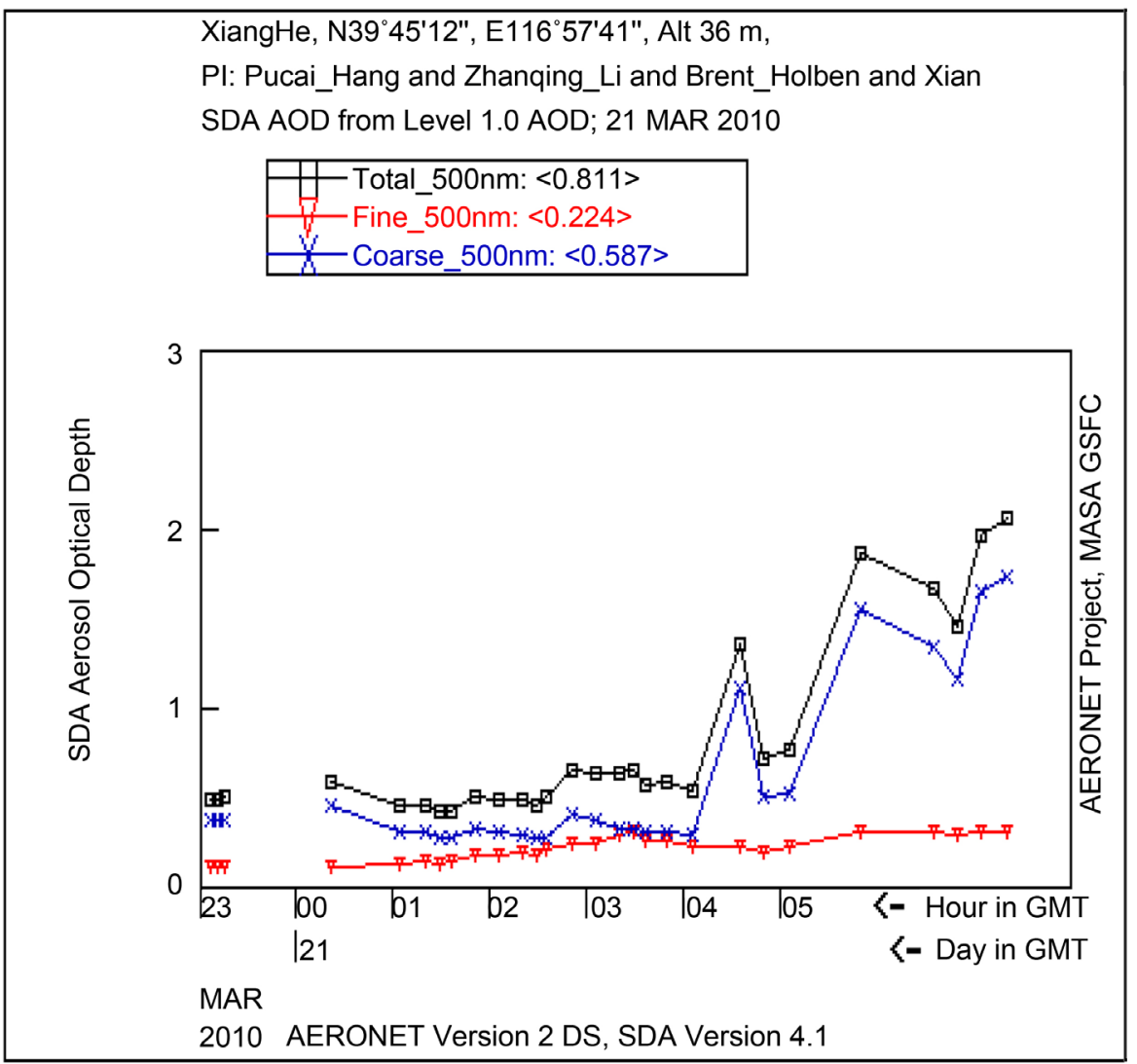

(b) 


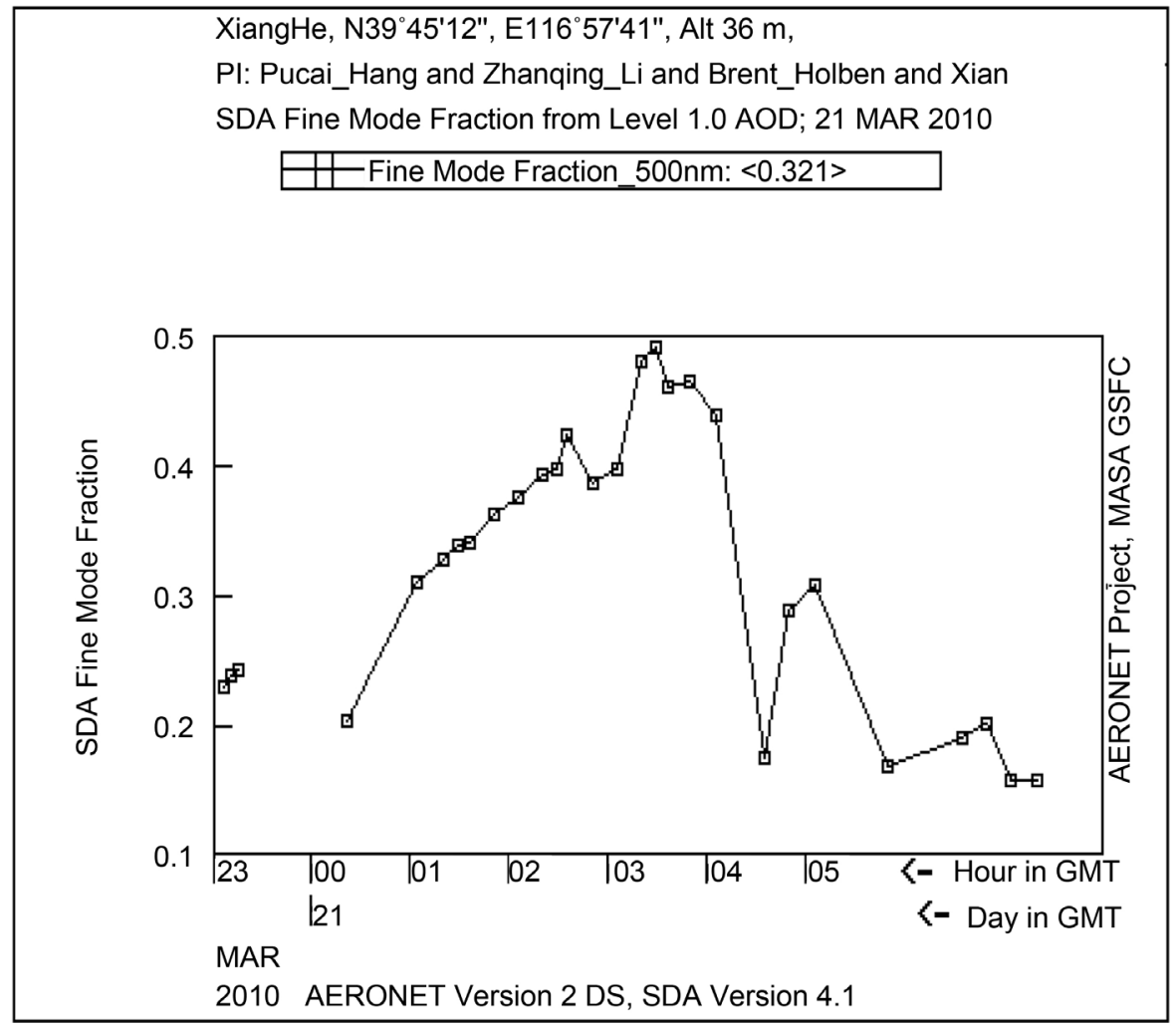

(c)

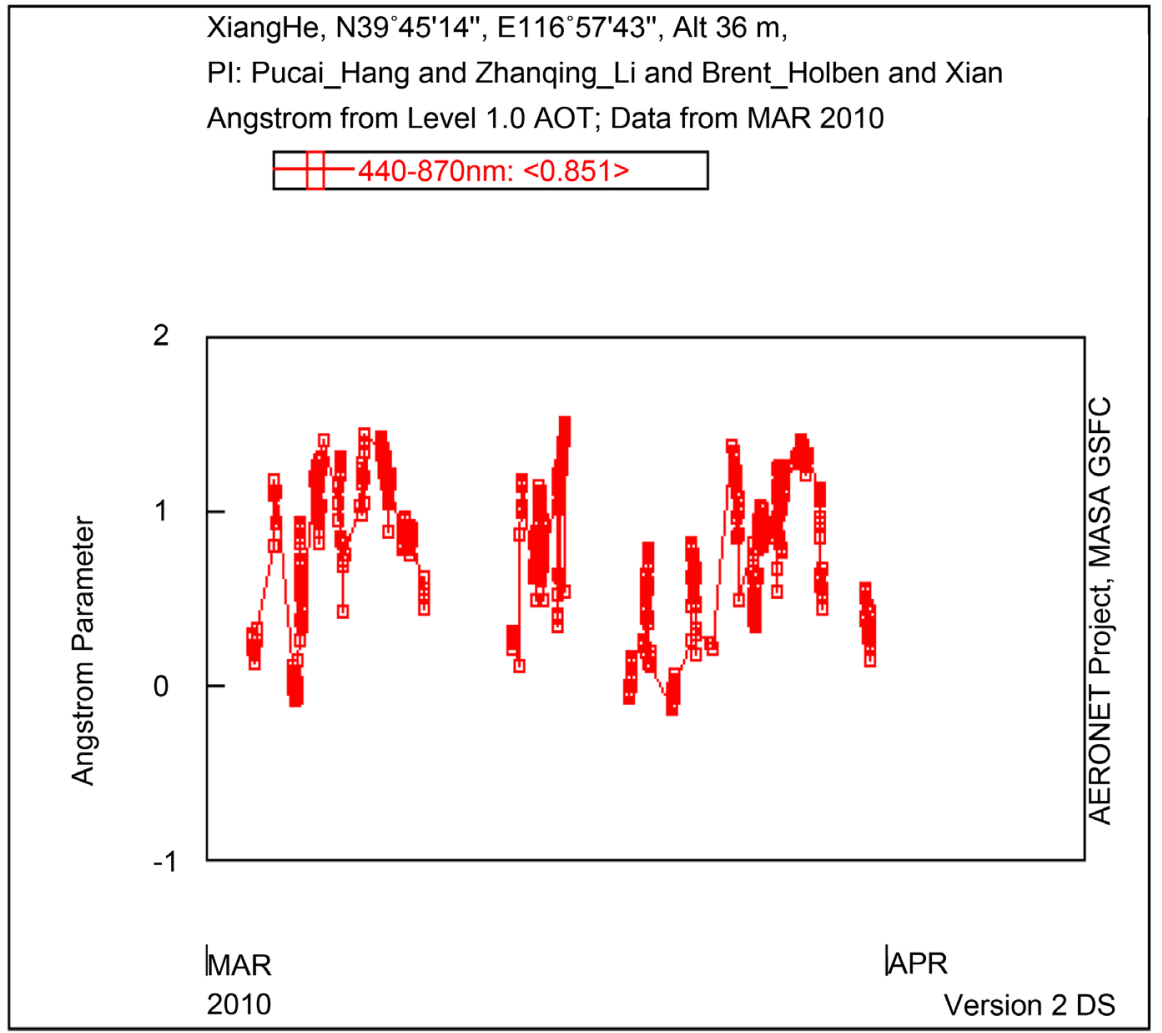

(d)

Figure 4. Observed optical parameters from AERONET at Xianghe, Beijing during Mar. 21 (a) AOD, (b) SDA AOD, (c) SDA fine mode fraction, (d) Angstrom parameter. 


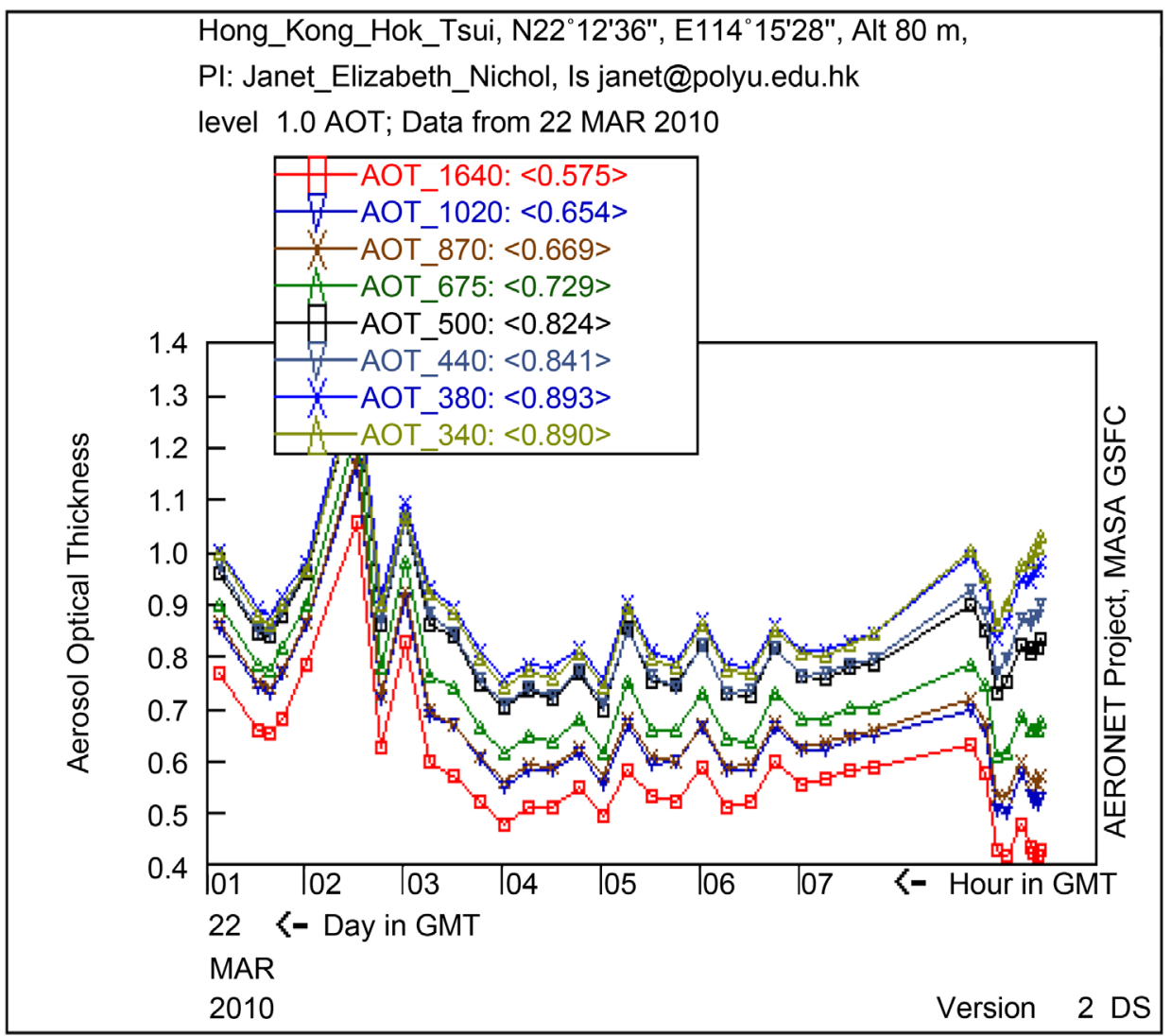

(a)

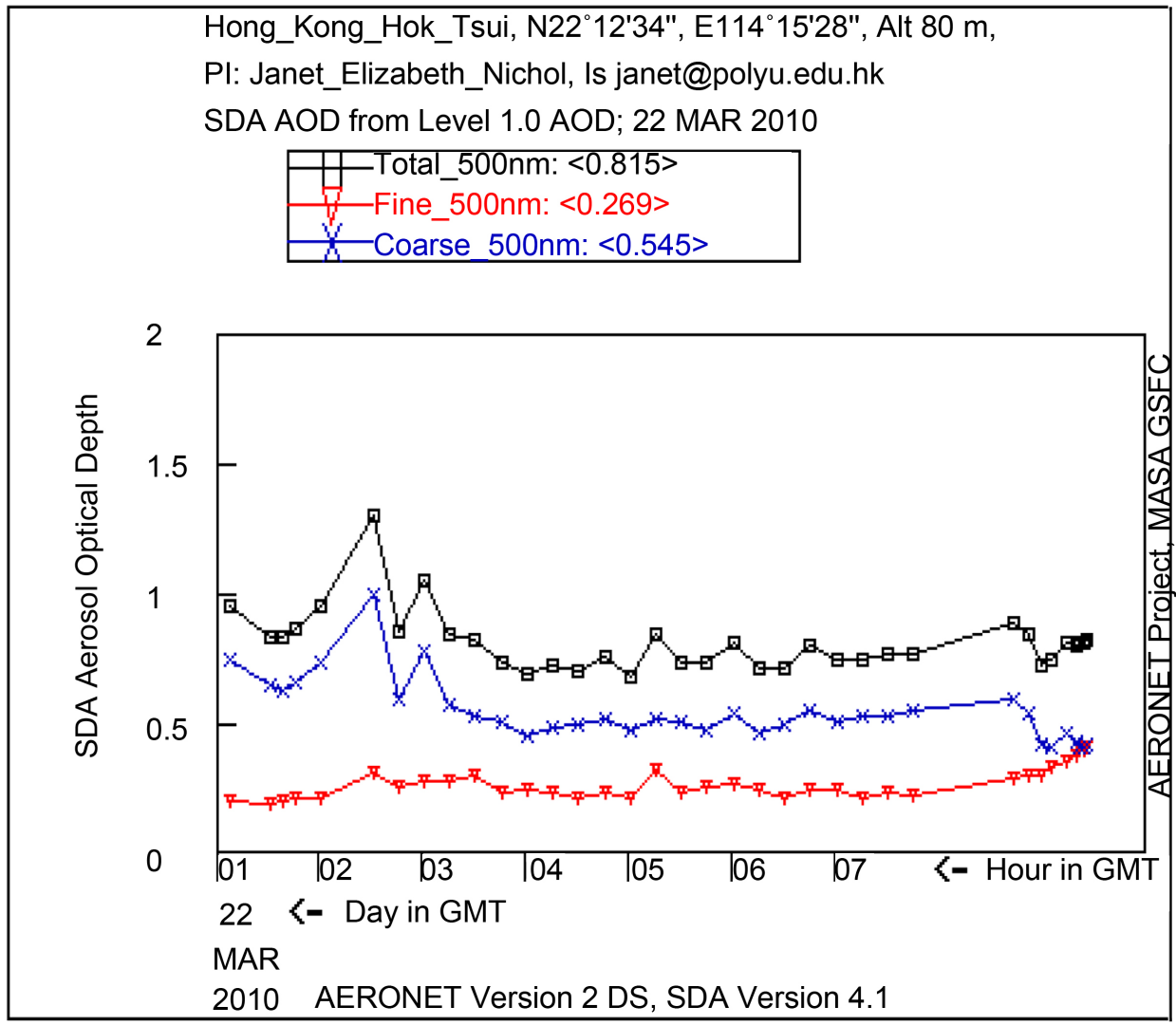

(b) 


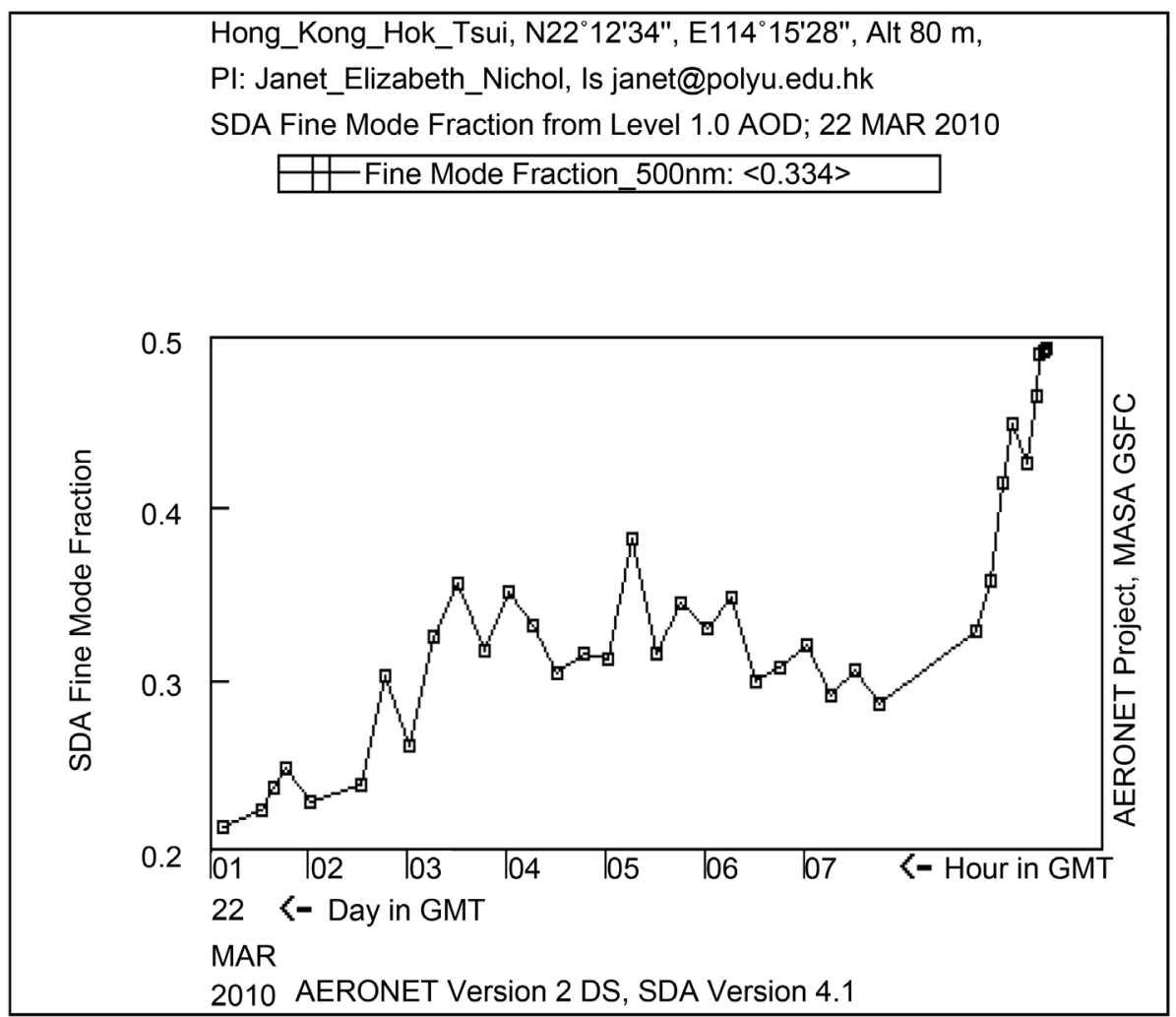

(c)

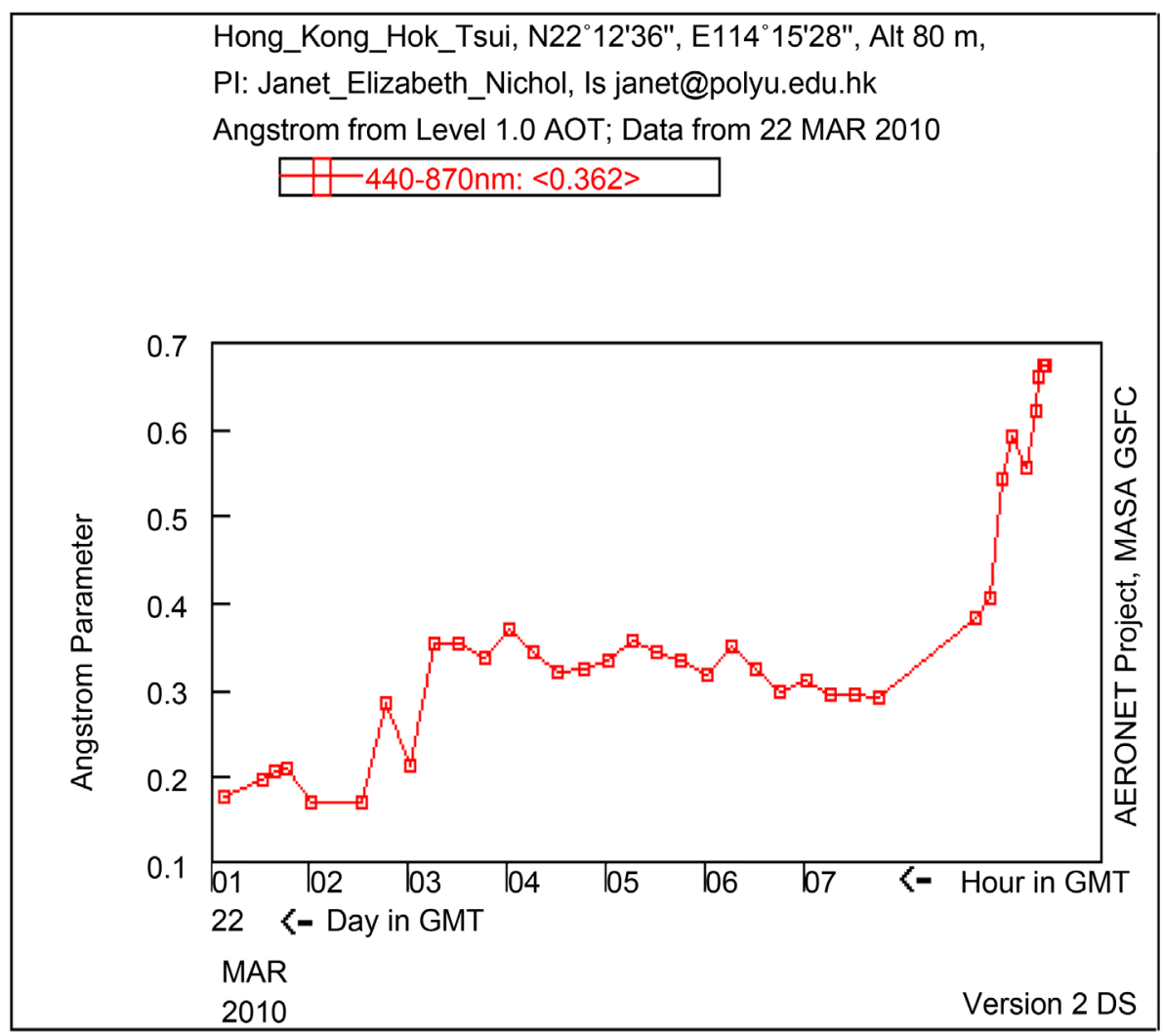

(d)

Figure 5. Observed optical parameters from AERONET at HokTsui, Hong Kong during Mar. 22 (a) AOD, (b) SDA AOD, (c) SDA fine mode fraction, (d) Angstrom parameter. 


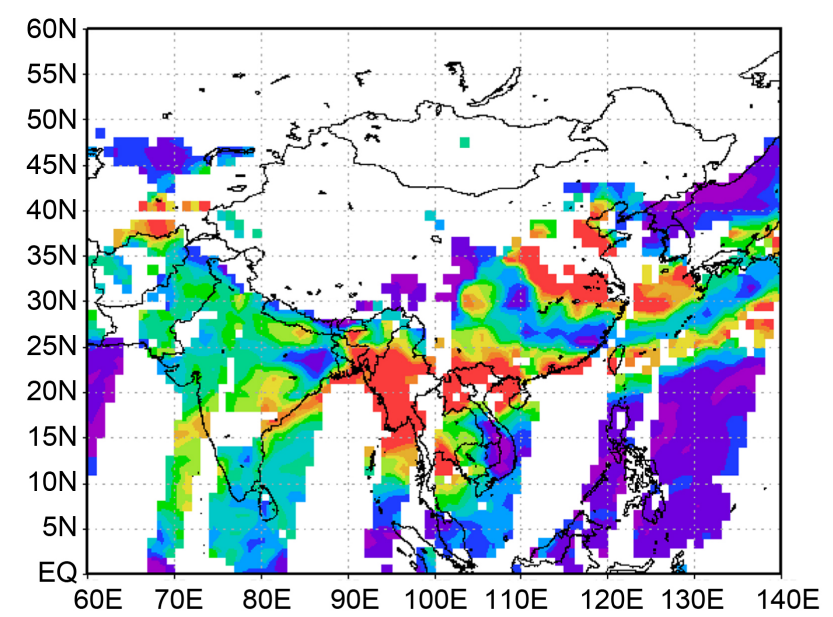

(a)

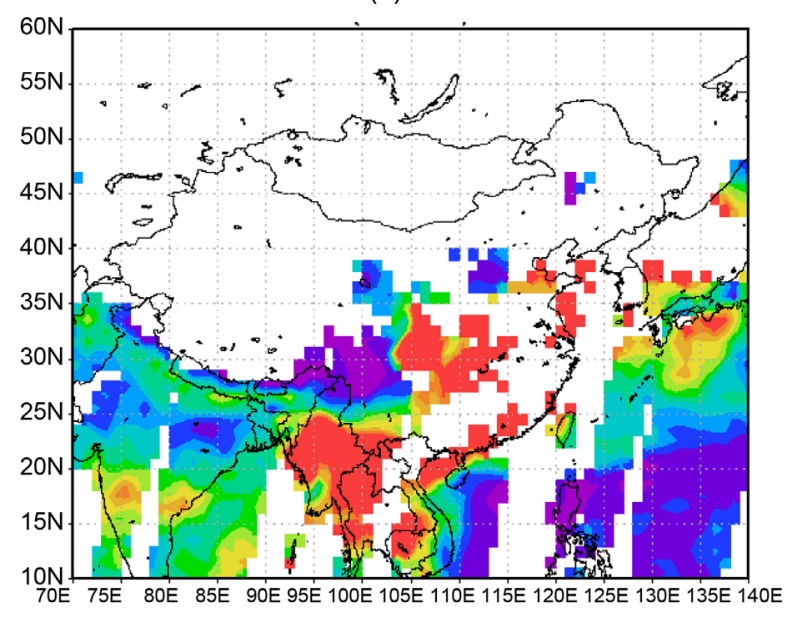

(c)

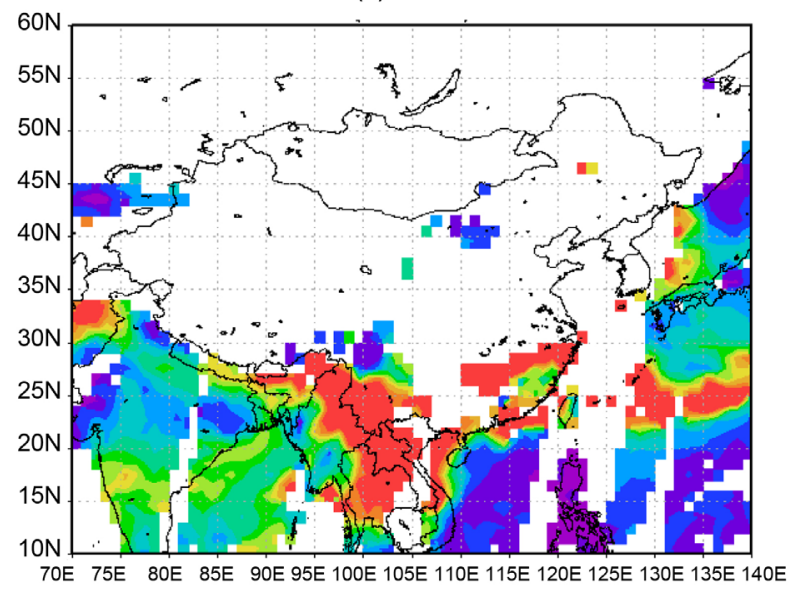

(e)

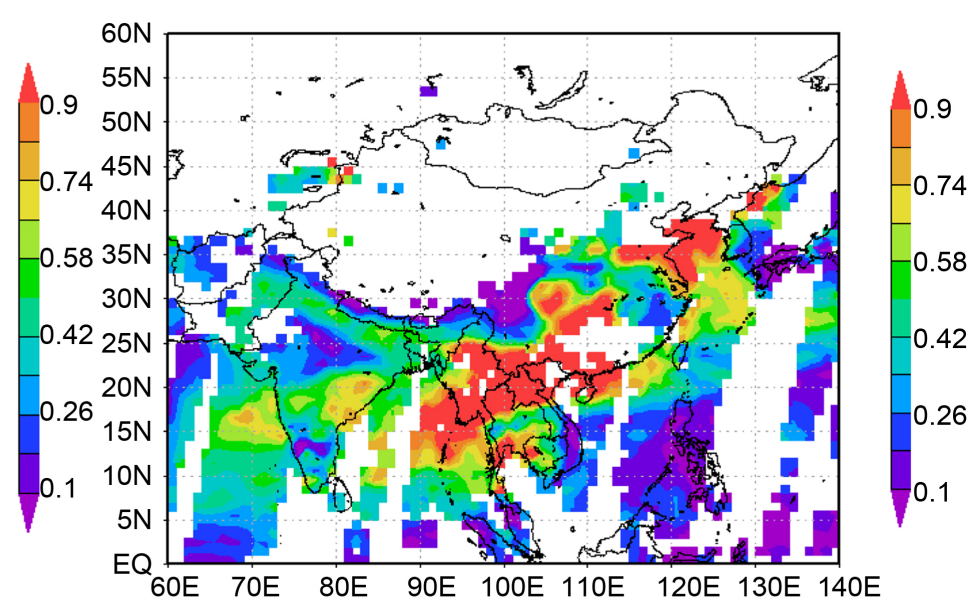

(b)

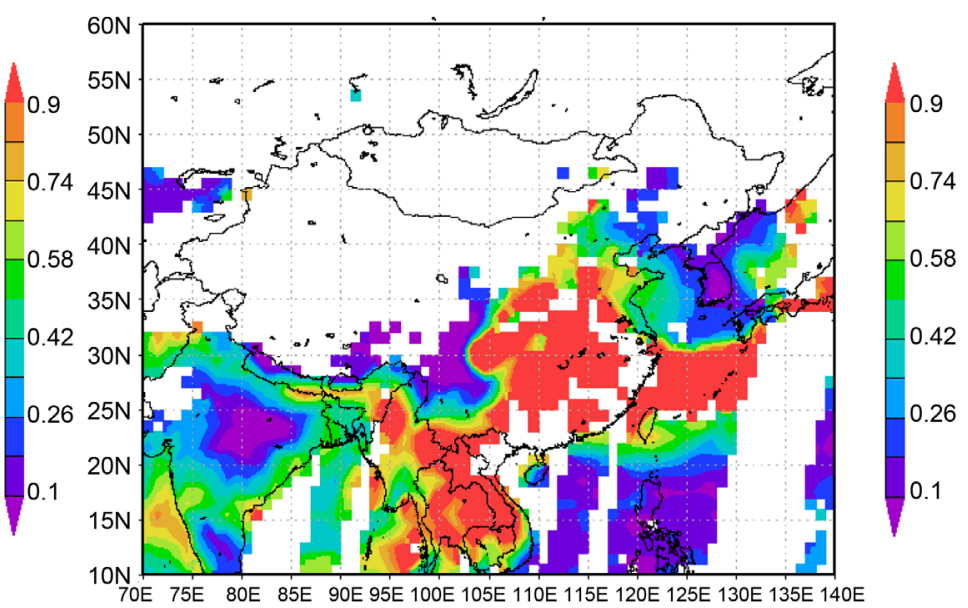

(d)

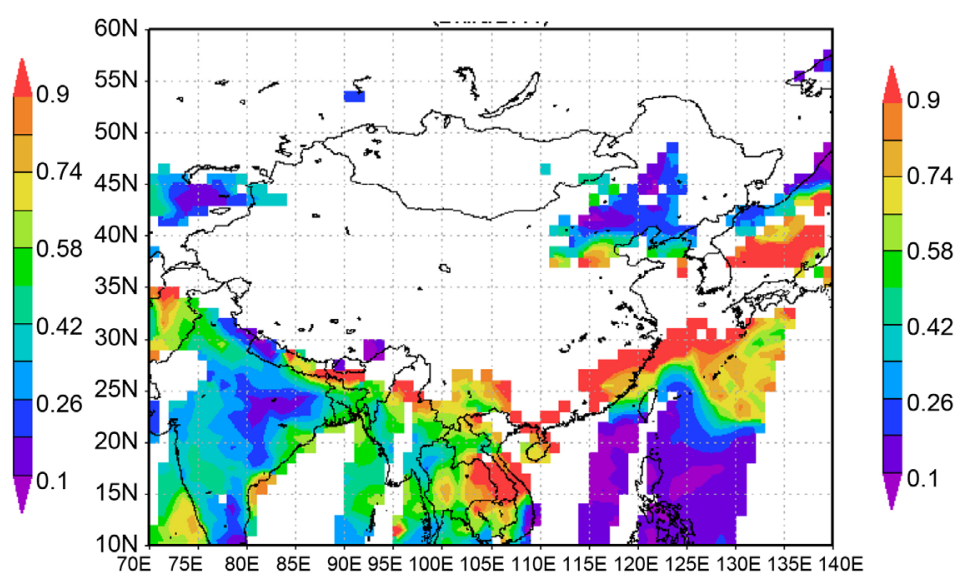

(f)

Figure 6. MODIS AOD (550 nm) distribution during Mar. 18-23.

AOD decrease, small mode fraction as well as angstrom parameter increase, indicating the importance of fine particles when the impact of dust became weaker.

Figure 8 presents time-longitude cross section of aerosol optical parameters. From Figure 8(a), high AOD center move from mid-latitude $(40 \mathrm{~N}-45 \mathrm{~N})$ to low latitude $(20 \mathrm{~N}-25 \mathrm{~N})$, and then back to mid-latitude $(35 \mathrm{~N}-40 \mathrm{~N})$, showing the transport of dust 
Time Series, Area Statistics

(Region: 70E-140E, 10N-60N)

Aerosol Optical Depth at $550 \mathrm{~nm}$ (MOD08_D3.051)

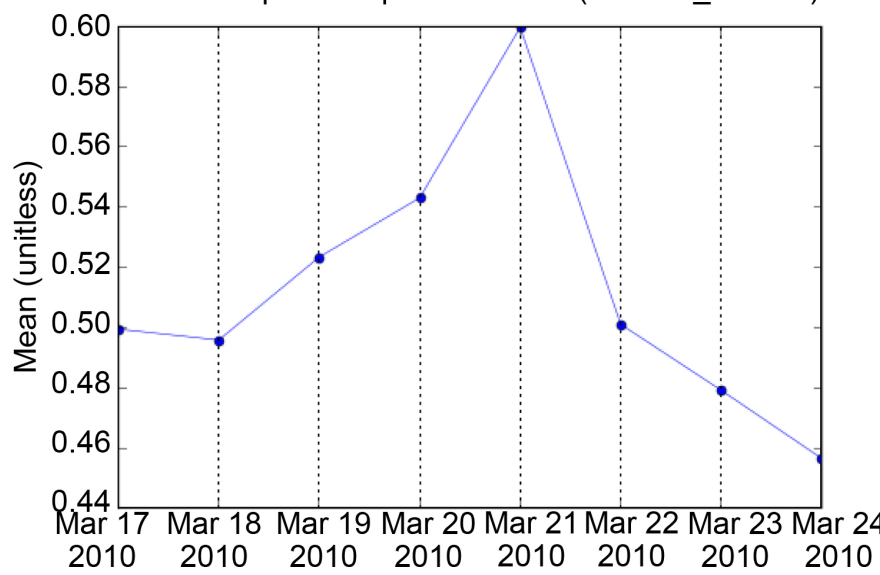

(a)

Time Series, Area Statistics

(Region: 70E-140E, 10N-60N)

Angstrom 470/660nm-Land (QA-w) (MOD08_D3.051)

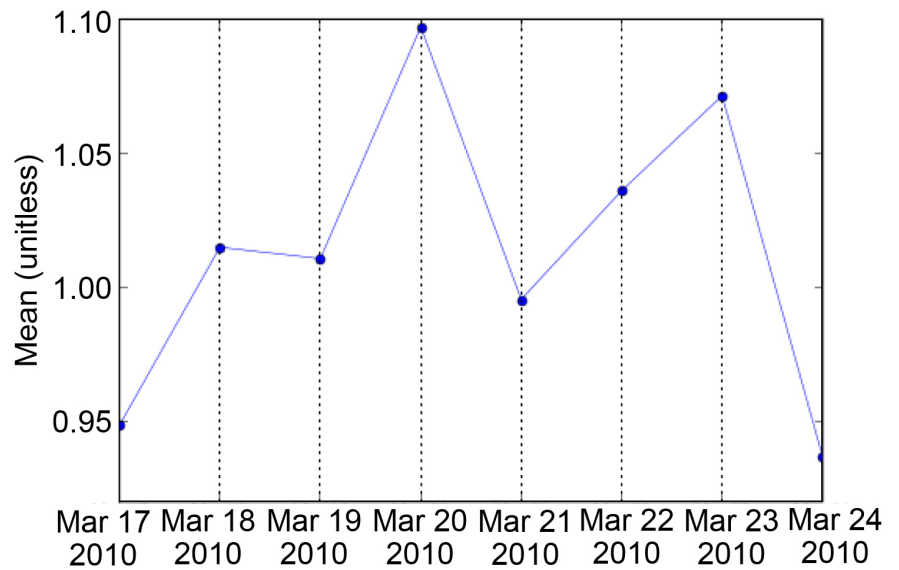

(c)
Time Series, Area Statistics

(Region: 70E-140E, 10N-60N)

Aerosol Small Mode Fraction (MOD08_D3.051)

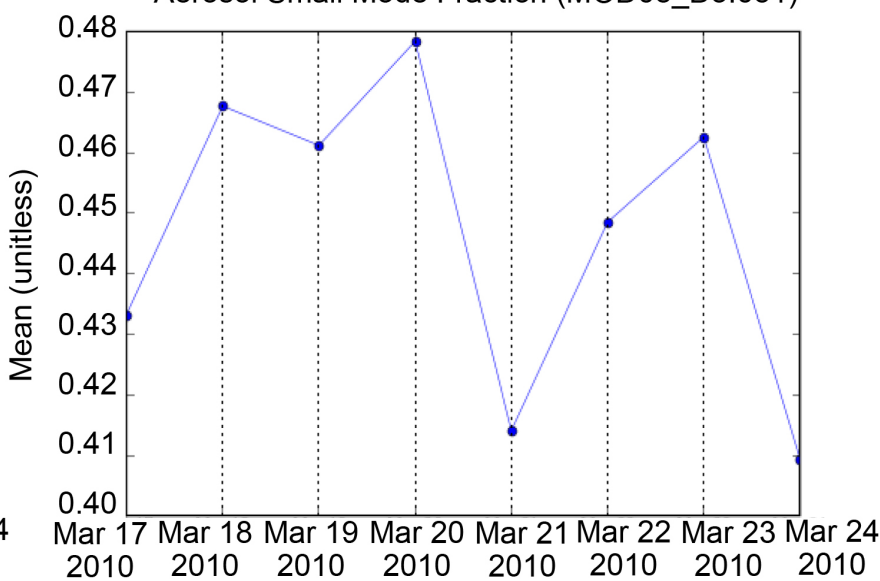

(b)

Figure 7. Area averaged time series of optical parameters during Mar. 17-24 (a) AOD, (b) Aerosol fraction mode fraction, (c) Angstrom parameter.

from north to south. On the same days, aerosol small mode optical depth decrease with the increase of latitude (Figure 8(b)), showing more fine particles in the south and more coarse particles in the north. It reaches below $0.2-0.4$ at $45 \mathrm{~N}$ and $0.6-0.8$ at $10 \mathrm{~N}$, suggesting the coarse particles in the north and fine particles in the south. Angstrom parameter shows consistent pattern with aerosol small mode optical depth (Figure $8(c))$.

\subsubsection{Extinction Coefficient Vertical Profile}

The CALIPSO is the last in a sequence of several level 1 and level 2 algorithms that retrieve profiles of aerosol backscatter and extinction coefficients [34]. The profiles of mean extinction coefficient at $532 \mathrm{~nm}$ during Mar. 20 and 21 are illustrated in Figure 9. It shows that the dust can be transported up to $5 \mathrm{Km}$ in vertical direction. The extinction coefficient maximum of $0.35-0.4$ was observed at $1-3 \mathrm{Km}$, suggesting that strong 
MOD08_D3.005 Aerosol Aerosol Optical Depth at $550 \mathrm{~nm}$ [unitless]

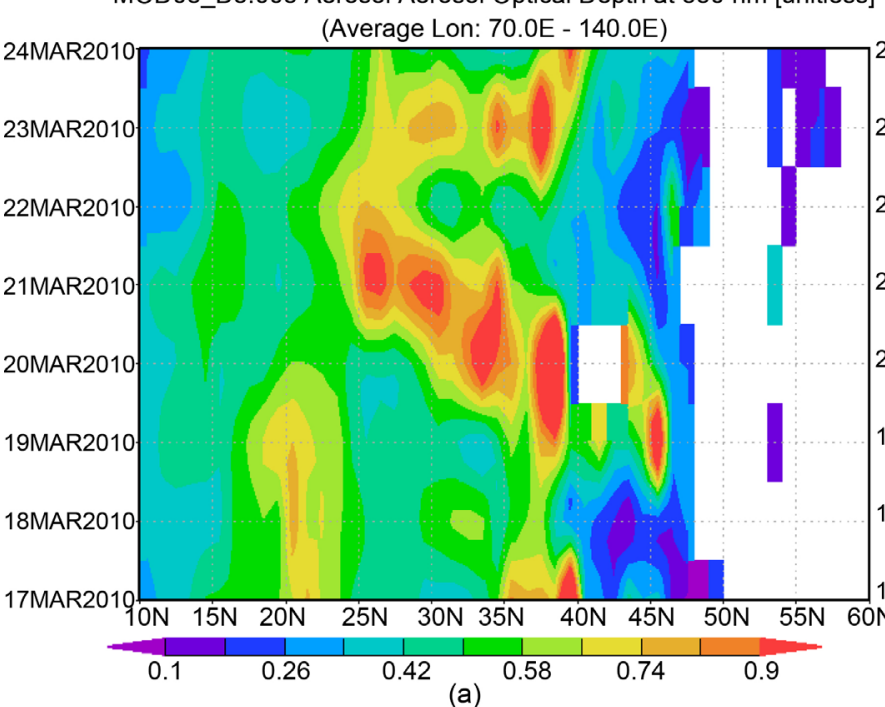

MOD08_D3.005 Aerosol 470/660nm-Land (QA-w) [unitless]

(Average Lon: 70.0E - 140.0E)

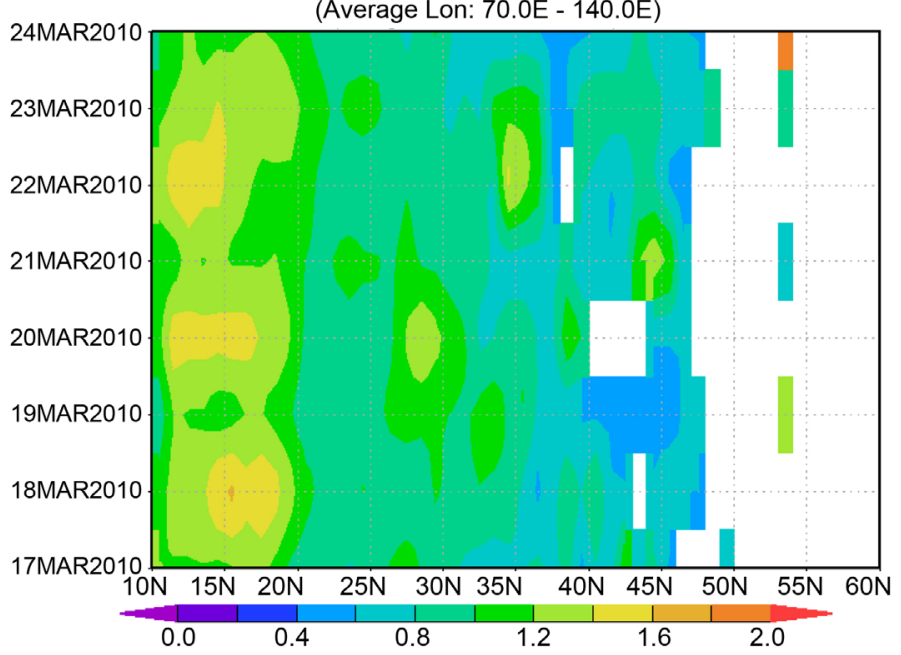

(c)

Figure 8. Time-longitude cross section of aerosol optical parameters (a) AOD, (b) Aerosol fraction mode fraction, (c) Angstrom parameter. boundary layer.

\subsubsection{Synopticweather}

Depicts the weather chart (http://218.94.36.199:5050/dmsg/map.htm) on Mar. 19-20. The Mongolia cyclone appeared on Mar. 17. A warm center of 21 in the northwest was found at $850 \mathrm{hPa}$ on Mar. 17 and 18. On the other hand, the cold high pressure generated near lake Balkhash on surface weather map. On Mar. 19, strong cold center appeared at the Caspian sea to lake Balkhash where north branch jet occurred. At 500 $\mathrm{hPa}$, the north branch trough in Mongolia and Hetao area split, cold high pressure at the surface is located at north Xinjiang and west Mongolia with central pressure greater than $1040 \mathrm{hPa}$. At the mean time, warm low pressure was developing in the east of Mongolia. The extremely unstable stratification condition was formed, which is beneficial to the exchange of cold and warm air in upper and lower levels. The strong 


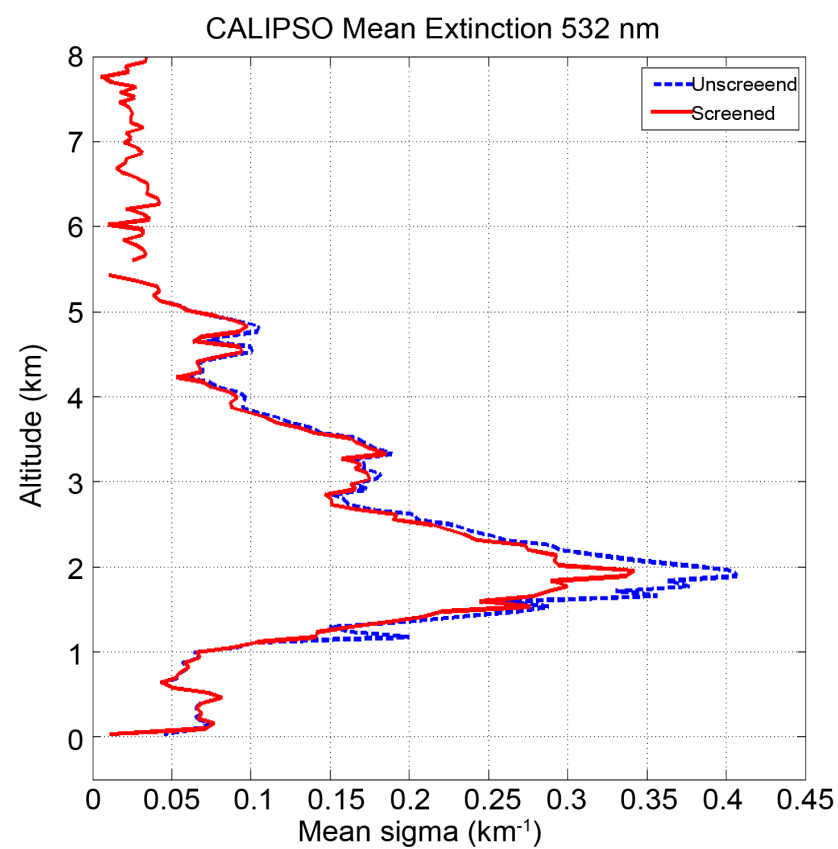

(a)

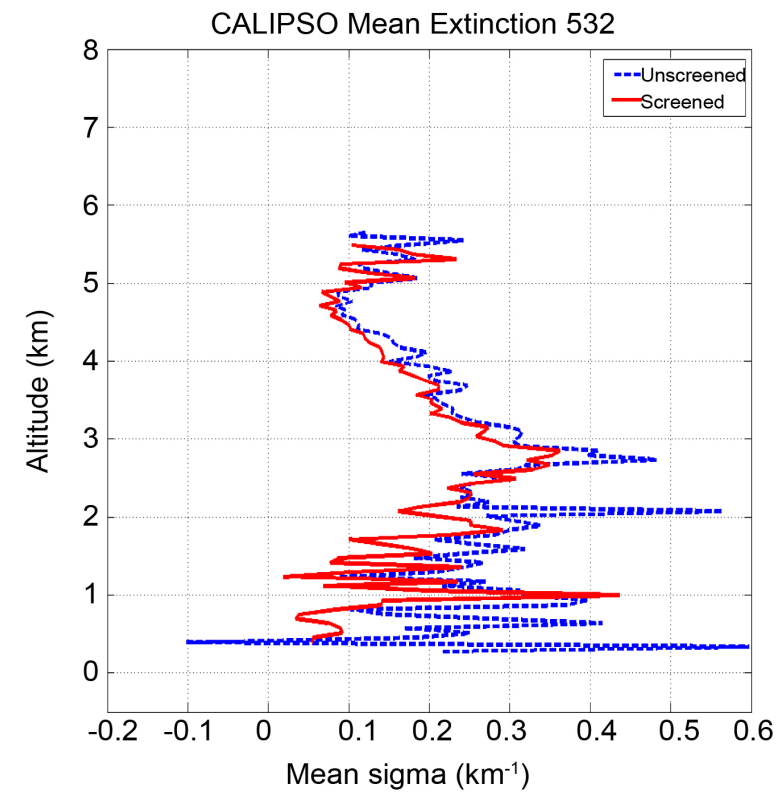

(c)

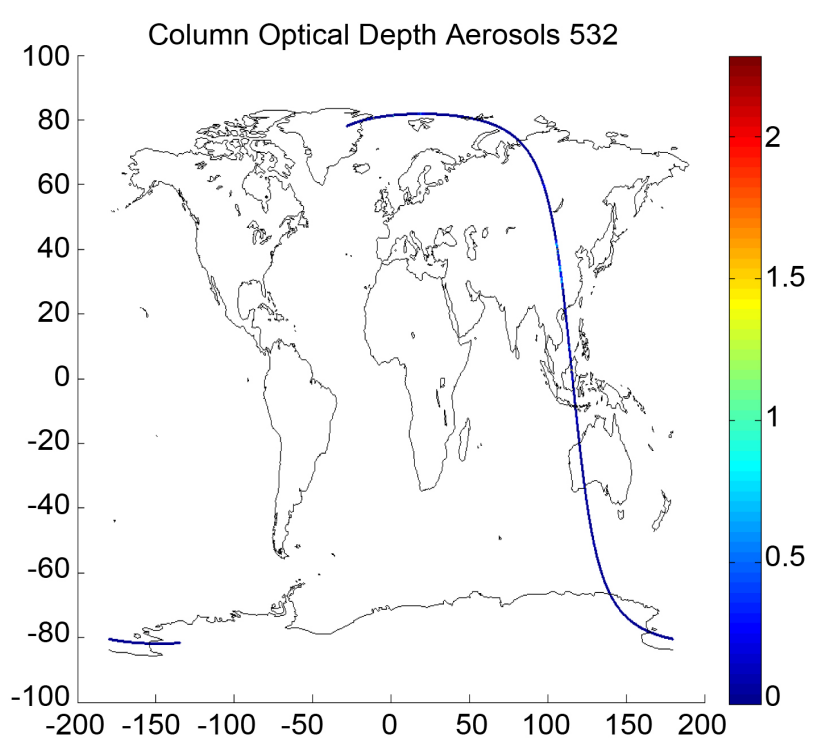

(b)

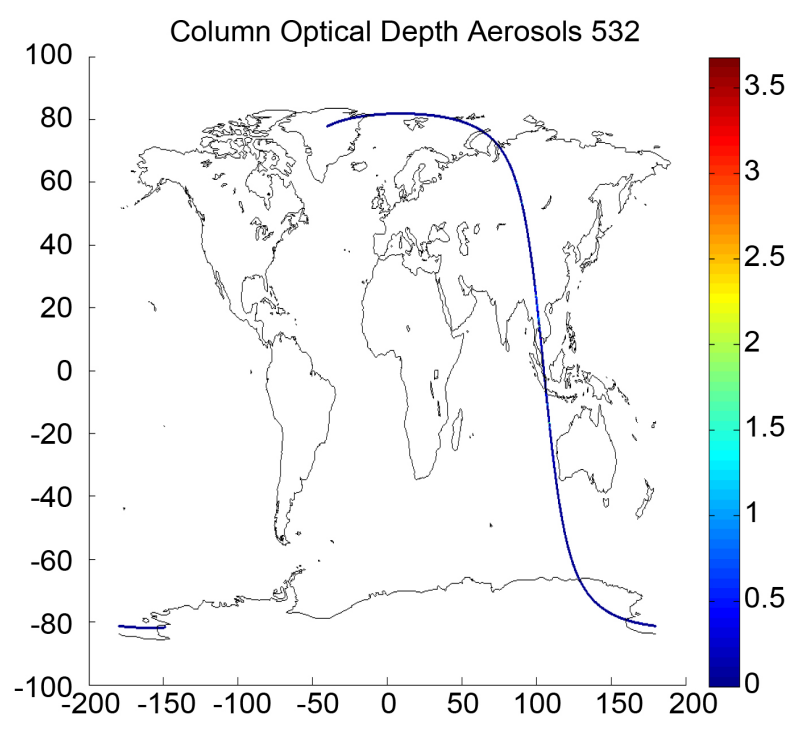

(d)

Figure 9. Profile of CALIPSO mean extinction at $532 \mathrm{~nm}$ and lidar moving path on Mar. 20 ((a), (b)) and Mar. 21((c), (d)).

intersection of cold and warm front results in the great gradient of temperature and pressure, surface wind speed becomes very strong, resulting in breakout of dust storm in Mongolia and central/west area of Inner Mongolia. Accompanying by the eastward of the synoptic system, dust can be transported to the south and east. This cold front is one of the important synoptic weather systems which are favorable for formation of dust storm [35].

\subsubsection{Backward Trajectory}

Three day backward trajectories arriving at Beijing, Nanjing and Hong Kong were cal- 
culated to explore the movement of the air mass. HYSPLIT4 was used to calculate backward trajectory with meteorological data from GDAS (Global Data Assimilation System) from NCEP (National Centers for Environmental Prediction). As shown in Figure 10, the air mass was originated from northwest, passing by Xinjiang, Inner

NOAA HYSPLIT MODEL

Backward trajectories ending at 1200 UTC 20 Mar 10 GDAS Meteorological Data

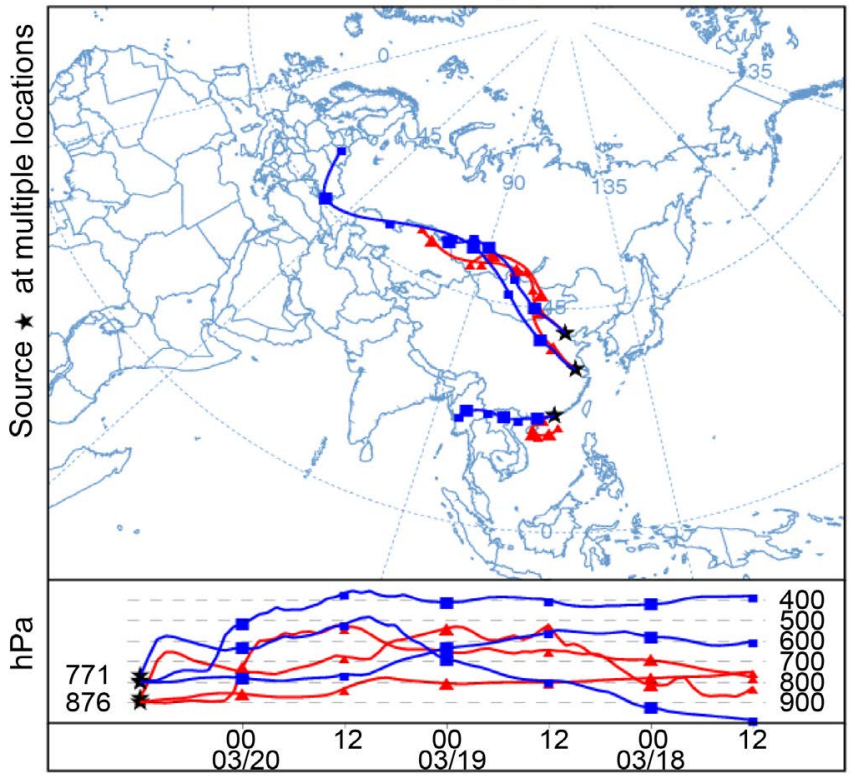

(a)

NOAA HYSPLIT MODEL

Backward trajectories ending at 1200 UTC 21 Mar 10 GDAS Meteorological Data

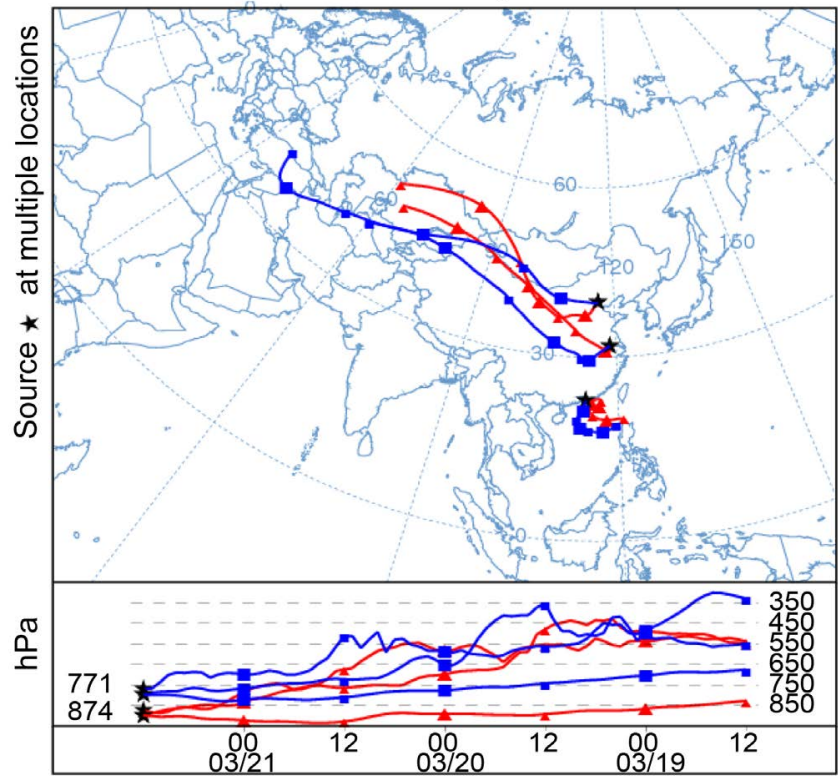

(b)

Figure 10. $72 \mathrm{~h}$ backward trajectories to Beijing, Nanjing and Hong Kong on (a) Mar. 20 and (b) Mar. 21. 
Mongolia, Gansu, Hebei etc., and then reaching Beijing and Nanjing which were hit by the dust storm in Mar. 20 and Mar. 21, respectively. The dust storm affected Hong Kong in the Mar. 22. Three source regions are responsible of this strong dust event. Grini et al. (2005) had given the effects of soil erodibility and wind speed variability to the dust transport for the global atmosphere [36]. They are sandland in west and south of Mongolia, desert and sandland in west Inner Mongolia and its surrounding area, Hunshandak sandland in central Inner Mongolia. The calculated backward trajectories clearly exhibited the originations and transport path of dust aerosols.

\subsection{Numerical Simulations}

\subsubsection{WRF-Chem Simulation}

For numerical simulation of the dust event, two nesting domains were defined using Lambert projection. The large domain has grid spacing of $81 \mathrm{~km}$ with horizontal grids of $88 \times 75$, and the small domain has grid spacing of $27 \mathrm{~km}$ with horizontal grids of $85 \times$ 70. The model top pressure is set as $50 \mathrm{hPa}$, with 27 sigma layers in vertical. We used NCEP global reanalysis data with $1^{\circ} \times 1^{\circ}$ resolution as initial conditions and boundary conditions, the later were forced every six-hour. The ideal concentration profiles were used as initial and boundary conditions of chemical species. The RADM2 gas chemistry was chosen. MADE/SORGAM and GOCART aerosol module were selected for Shaw and Chin scheme, respectively. Other choices for physical processes are similar to Jiang (2008)'s work [37].

WRF-Chem (V3.2) model was integrated for 7 days staring from Mar. 17. Figure 11 illustrated the surface $\mathrm{PM}_{10}$ concentration simulated using two different dust schemes. Both Shaw and Chin schemes show similar patterns of surface $\mathrm{PM}_{10}$ concentration and dust moving path. However, Shaw scheme predicted larger coverage of dust aerosol and stronger dust emission in Mongolia compared to Chin scheme.

\subsubsection{Comparison with Observational Data}

The simulated daily average surface concentrations of $\mathrm{PM}_{10}$ at 86 stations were compared with the observations. These results are shown in Figure 12. Both schemes over predicted the $\mathrm{PM}_{10}$ concentration to certain extent. The $\mathrm{PM}_{10}$ coorelation coefficient between the model and the observation is 0.41 and 0.56 for Shaw scheme and Chin Scheme, respectively, with relative error of $60 \%$ and $57 \%$, respectively. It shows that Chin (2002) scheme is slightly better than Shaw (2008) scheme if taking $\mathrm{PM}_{10}$ concentration into account. There may be several reasons to explain the difference. First, the wind erosion scheme is very important in dust simulation, which determines how much dust was emitted into the air. Second, meteorology simulation play crucial role in dust transport and deposition, which determine where the dust can be transported. The input parameters, such as landuse, landcover and soil erosion data, become the third factors on the estimation of dust production [38]. The three aspects need to be improved to get more satisfied results.

\subsubsection{Comparison with CUACE-Dust and RegCCMS}

Figure 13 presents comparison of the simulated surface concentration of $\mathrm{PM}_{10}$ between CUACE-Dust and RegCCMS. Both of the model show similar patterns of surface $\mathrm{PM}_{10}$ 


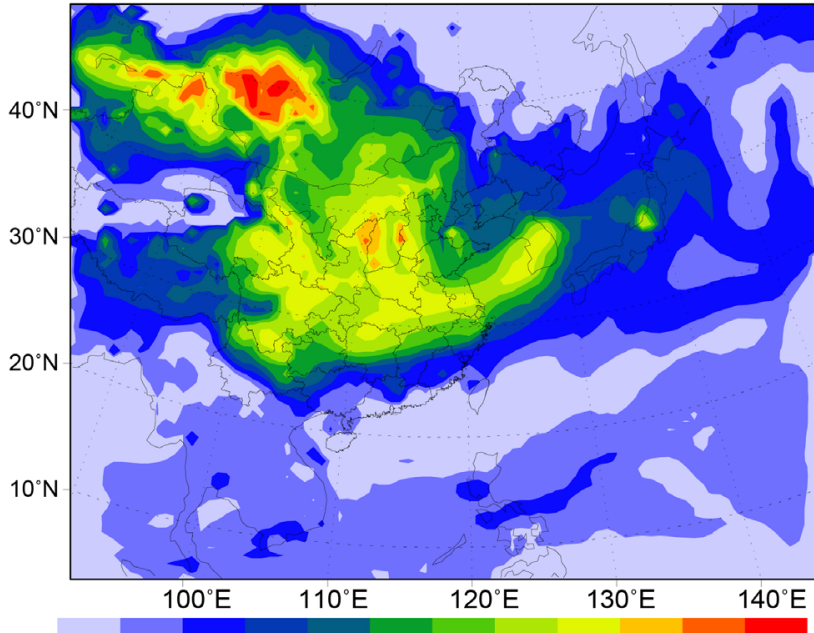

$10 \quad 20 \quad 50 \quad 100 \quad 200400 \quad 600 \quad 1000150020003000$

(a)

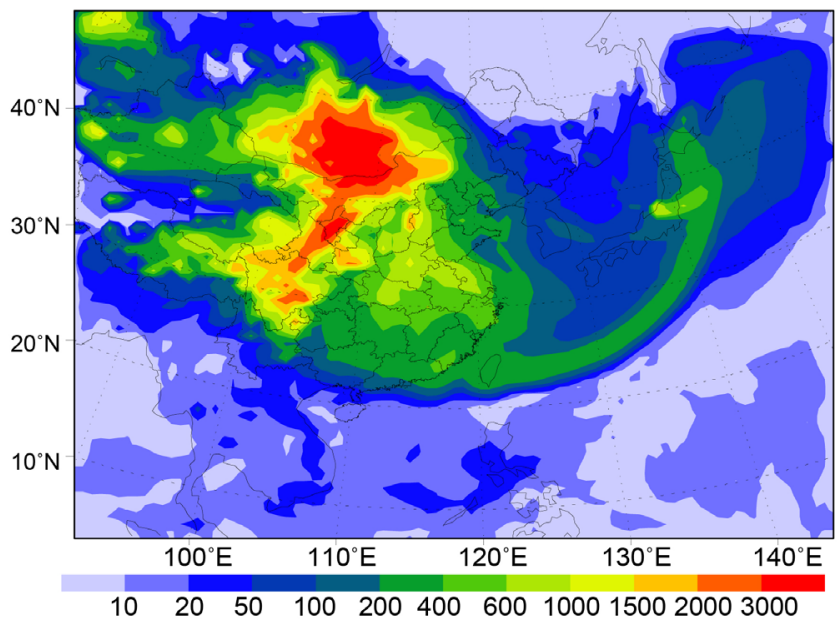

(b)

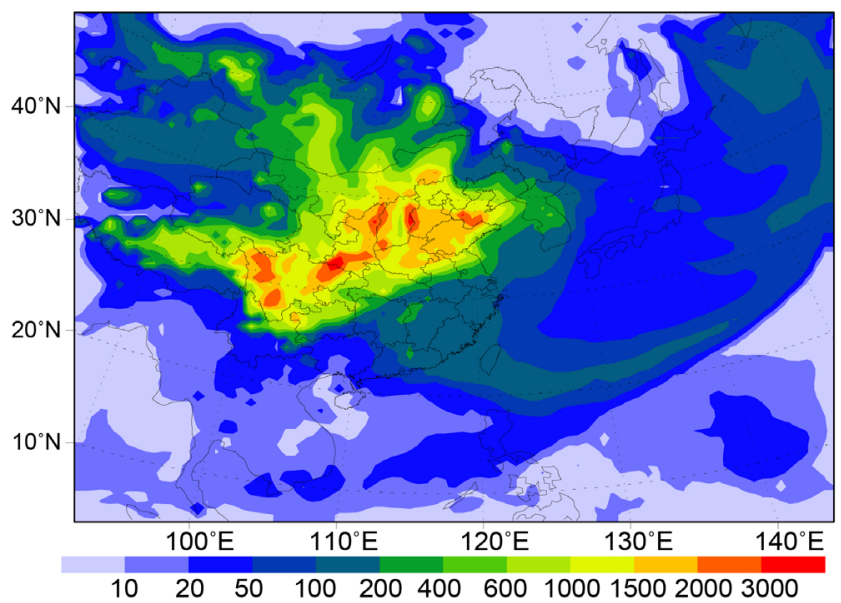

(c)

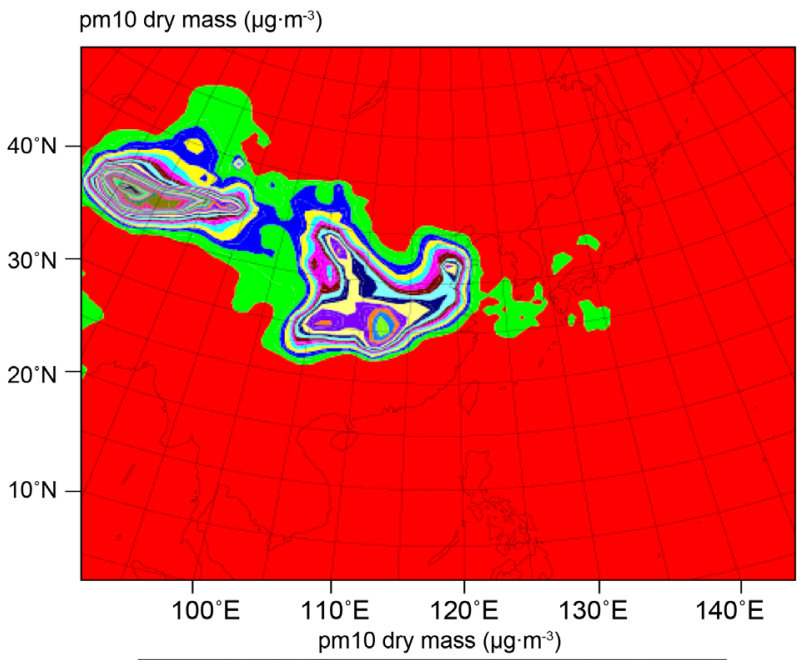

एा

03006009001200150018002100240027003000

(d)

pm10 dry mass $\left(\mu \mathrm{g} \cdot \mathrm{m}^{-3}\right)$

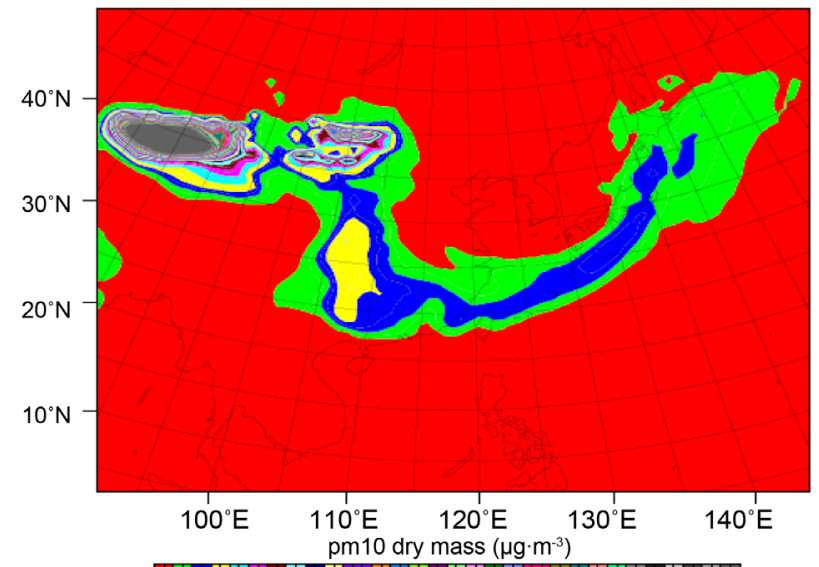

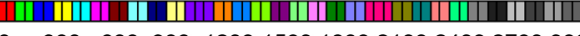

03006009001200150018002100240027003000

(e)

pm10 dry mass $\left(\mu \mathrm{g} \cdot \mathrm{m}^{-3}\right)$

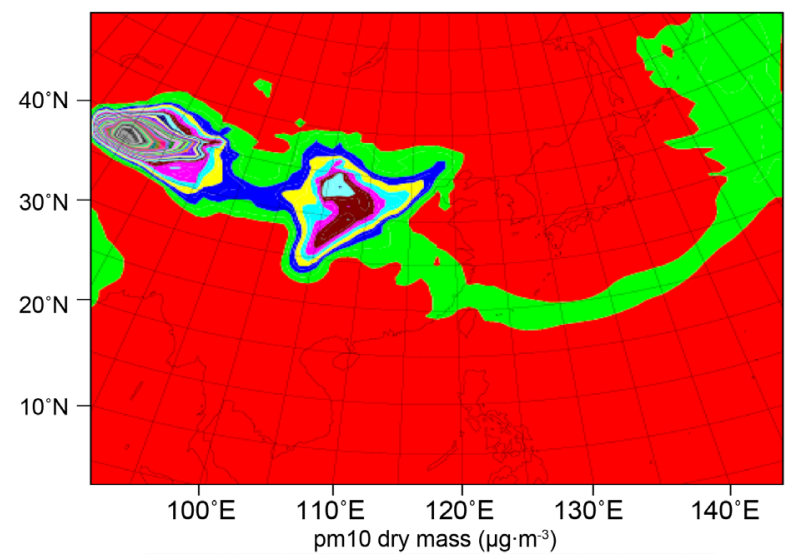

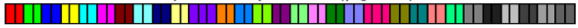

03006009001200150018002100240027003000

(f)

Figure 11. $\mathrm{PM}_{10}$ surface daily mean concentration Shaw ((a), (b), (c)) and Chin ((d), (e), (f)) in WRF-Chem during Mar. $20-22$ $\left(\mu \mathrm{g} / \mathrm{m}^{3}\right)$. 


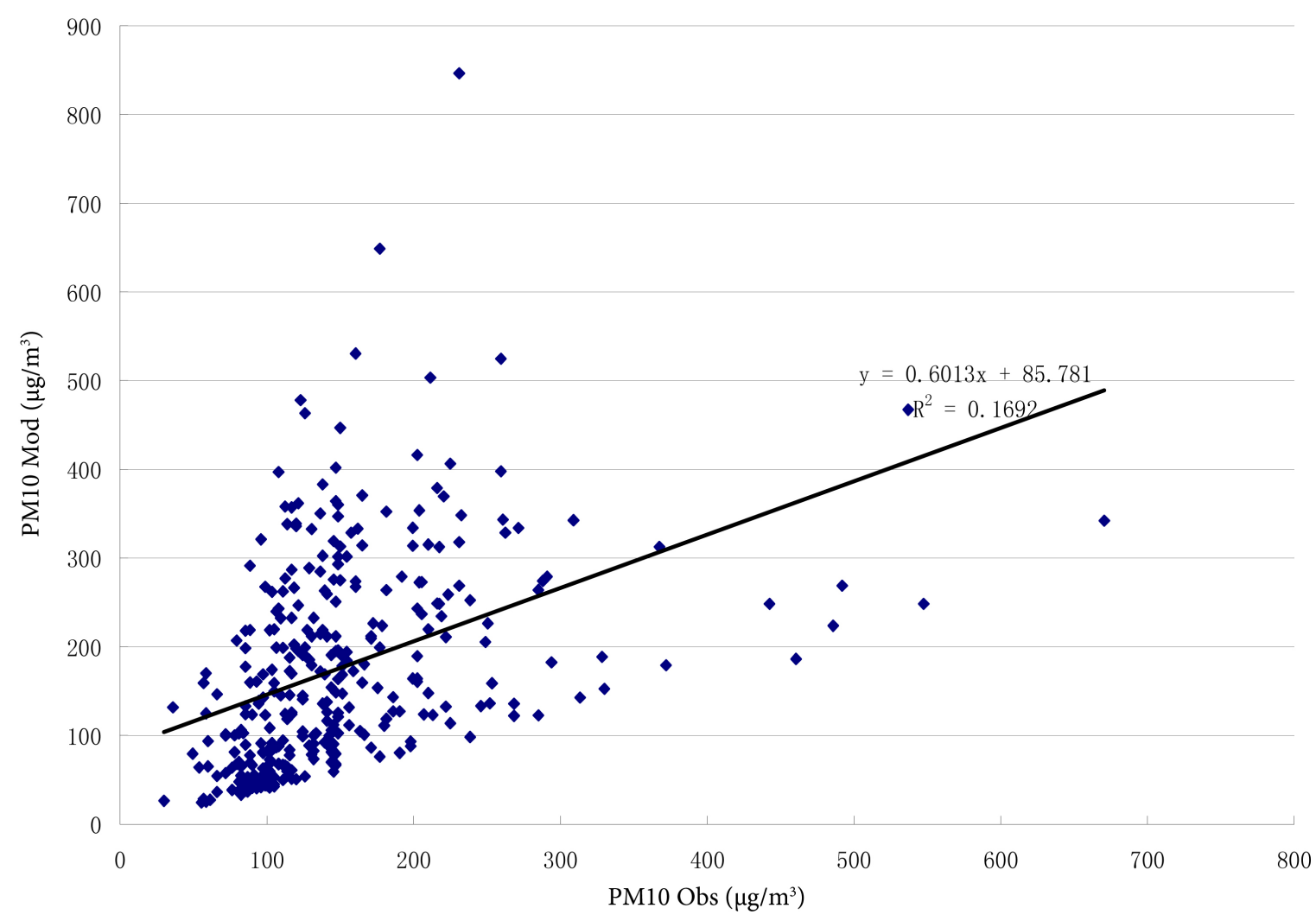

(a)

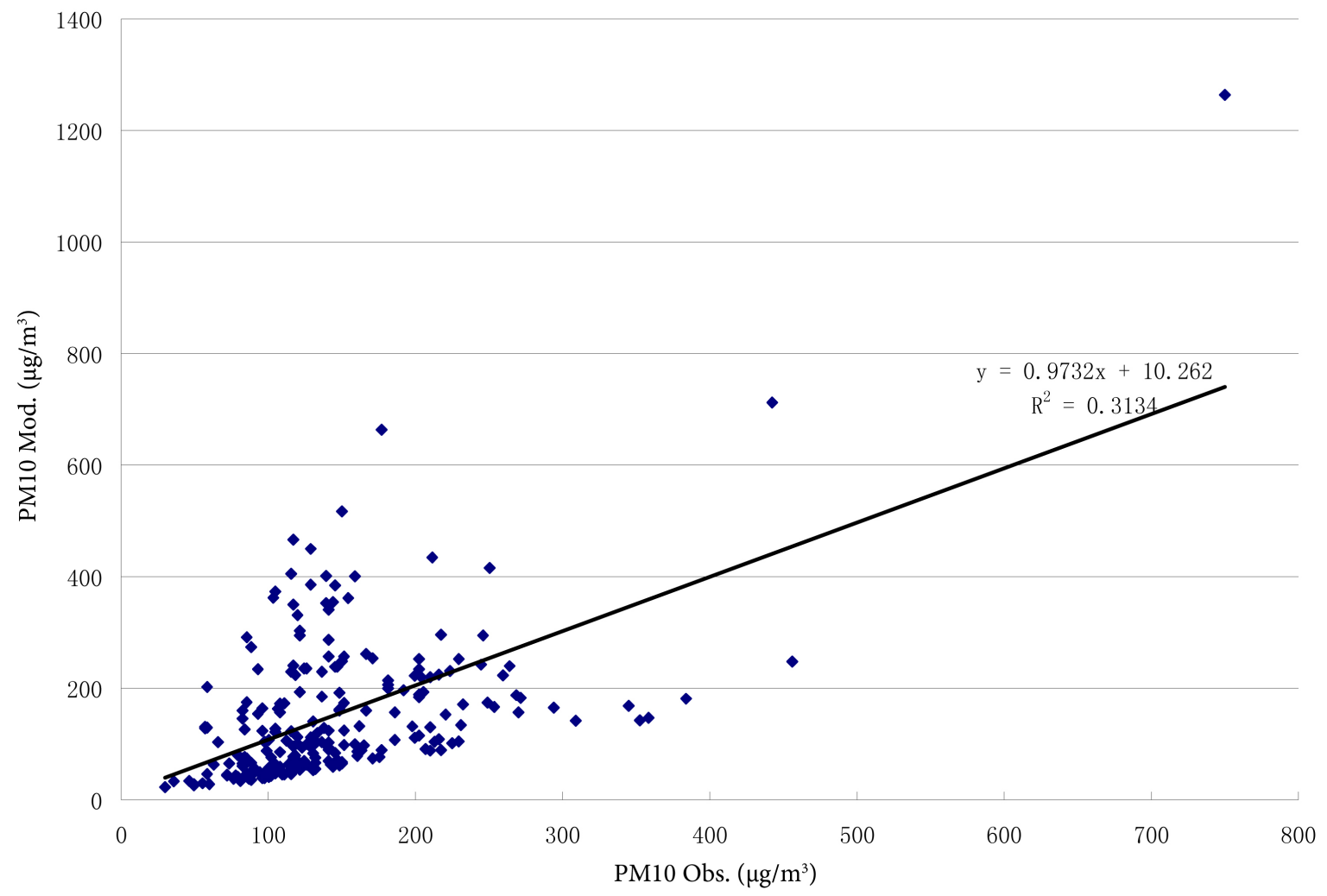

(b)

Figure 12. Daily $\mathrm{PM}_{10}$ surface concentration from observation and WRF-Chem for Shaw scheme and Chin scheme $\left(\mu \mathrm{g} / \mathrm{m}^{3}\right)$. 

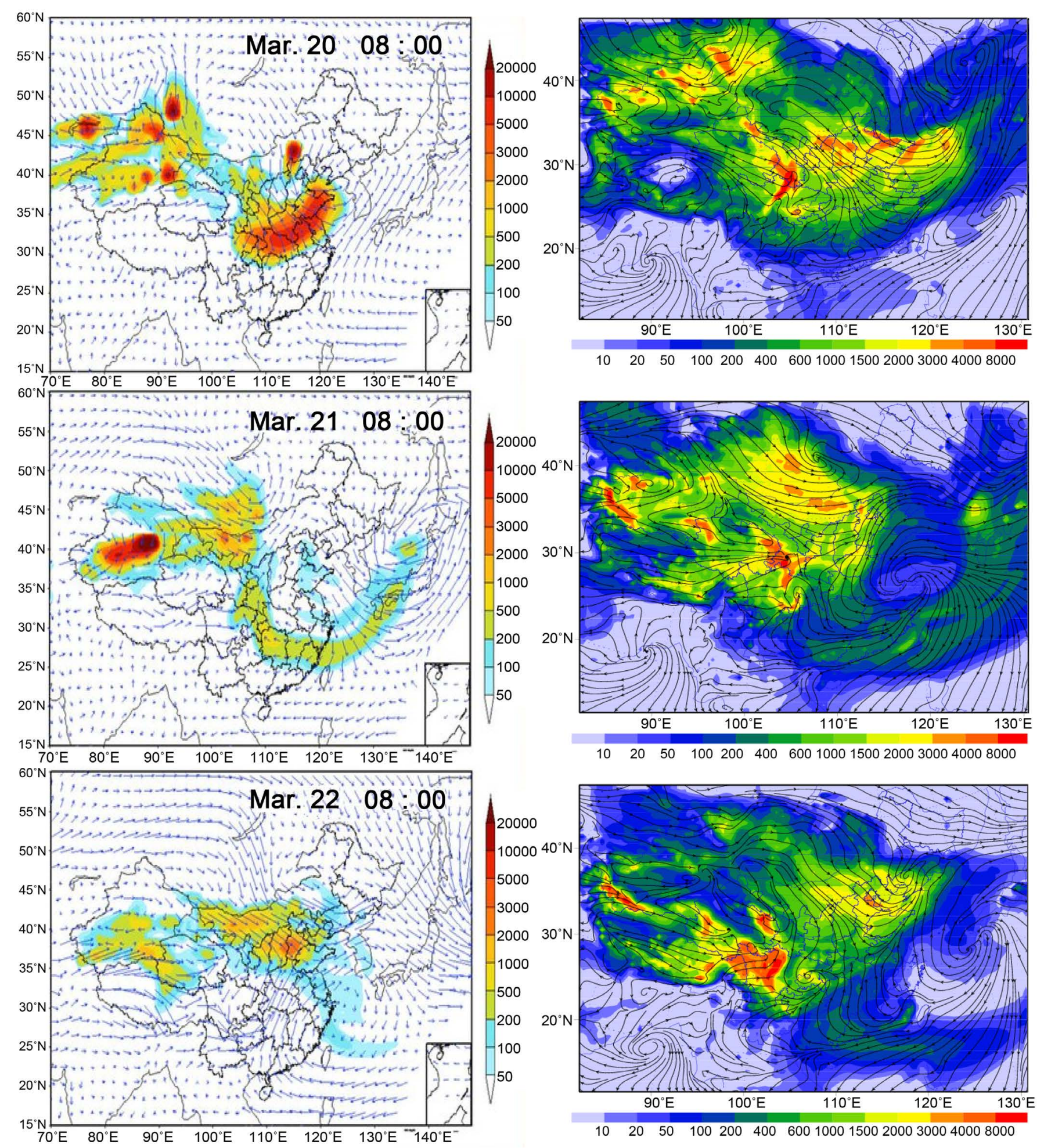

Figure 13. $\mathrm{PM}_{10}$ surface concentration by CUACE-Dust and RegCCMS during Mar. 20-22 ( $\left.\mu \mathrm{g} / \mathrm{m}^{3}\right)$.

concentration with WRF-Chem over dust source regions as well as downstream area, especially in Xinjiang and Mongolia. This dust storm is primarily originated from Mongolia, however there is also sand dust coming from Xinjiang. In general, CUACEDust predicted high $\mathrm{PM}_{10}$ concentration with narrow coverage, while $\mathrm{PM}_{10}$ level is 
underestimated and dust is widely spread and transported to Southeast China for RegCCMS. Further, dust emission in Mongolia is better estimated for RegCCMS than CUACE-Dust in consideration of the spatial distributions. The total dust of $120 \mathrm{Mt}$ was roughly estimated by RegCCM, in which $64 \%$ was deposited and $36 \%$ was stayed in the air for this dust storm episode.

\section{Conclusions}

Dust storm has become one of the important sources of severe air pollution episode in China, especially during spring season. A serious dust storm formed in Mongolia on Mar. 19, 2010. Then it was transported to the northern China, and inhalable particles increased in Gansu, Inner Mongolia, Beijing and Shandong provinces. The dust then spread to the south of Yangtze River region two days later. The area with large API shifted from Northwest to Southeast. Dust aerosols were transported to Hubei, Anhui, Jiangsu and Zhejiang provinces in Central and East China on Mar. 21 and then Guangdong, Fujian provinces and Hong Kong in South China on Mar. 22. Air pollution induced by dust storm was alleviated in coastal regions and other areas of China since Mar. 23 due to the end of long range transport of dust aerosol. This serious dust event has close relations to the increasing temperature, strong wind and the development of Mongolia cyclone.

The Version 3.2 of WRF-Chem was applied to simulate this dust storm case. The surface observations of $\mathrm{PM}_{10}$ concentration and AOD from MODIS were used to validate the model performance. It shows that WRF-Chem has the ability to simulate the production, transportation and deposition of the dust storm. Considering the two dust schemes in WRF-Chem, Chin (2002) scheme presents much better results in terms of $\mathrm{PM}_{10}$ surface concentration simulation. However, Shaw (2008) scheme gives more reasonable spatial distribution of dust aerosols. WRF-Chem as well as CUACE-Dust and RegCCMS show performance in simulation of surface $\mathrm{PM}_{10}$ concentration and transport path of dust aerosols. Although large amount of dust was emitted into the air, most of which was deposited during the long range transport to downstream regions.

The studies in this paper suggested that estimation of sand emission is crucial in numerical simulation of dust intensity, which can result in different $\mathrm{PM}_{10}$ and AOD pattern in terms of airborne particulate. WRF-Chem is assessed to be a useful tool in simulation of dust event. However, in order to get more realistic results, assimilation of different aerosol data into the model are highly recommended to improve the simulation on concentration and optical parameters. This work will be addressed in another paper.

\section{Acknowledgements}

We acknowledge the MODIS mission scientists and associated NASA personnel for the production of the data used in this research effort. Analyses and visualizations on MODIS data used in this study was produced with the Giovanni online data system, developed and maintained by the NASA GES DISC. The CALIPSO data were obtained from the NASA Langley Research Center Atmospheric Science Data Center. AERONET Principal Investigators are thanked for making their data available. This work was 
supported by the State Key Research and Development Program (2016YFC0208504, 2016YFC0203303) and National Natural Science Foundation of China (91544230, 41575145 and 41621005$)$.

\section{References}

[1] Gu, Y., Xue, Y., De Sales, F. and Liou, K.N. (2016) A GCM Investigation of Dust Aerosol Impact on the Regional Climate of North Africa and South/East Asia. Climate Dynamics, 46, 2353-2370. https://doi.org/10.1007/s00382-015-2706-y

[2] Han, Y., Wu, Y., Wang, T., et al. (2015) Characterizing a Persistent Asian Dust Transport Event: Optical Properties and Impact on Air Quality through the Ground-Based and Satellite Measurements over Nanjing, China. Atmospheric Environment, 115, 304-316. https://doi.org/10.1016/j.atmosenv.2015.05.048

[3] Marsden, N., Williams, P., Flynn, M., et al. (2016) Measuring the Temporal Evolution of Aerosol Composition in a Remote Marine Environment Influenced by Saharan Dust Outflow Using a New Single Particle Mass Spectrometer. EGU General Assembly Conference, Vienna, 17-22 April 2016, 13985.

[4] Zhang, X., Zhao, L., Tong, D.Q., et al. (2016) A Systematic Review of Global Desert Dust and Associated Human Health Effects. Atmosphere, 7, 158.

https://doi.org/10.3390/atmos7120158

[5] Tegen, I. and Fung, I. (1994) Modeling of Mineral Dust in the Atmosphere: Sources, Transport, and Optical Thickness. Journal of Geophysical Research, 99, 22897-22914. https://doi.org/10.1029/94JD01928

[6] Tegen, I. and Fung, I. (1995) Contribution to the Atmospheric Mineral Aerosol Load from Land Surface Modification. Journal of Geophysical Research, 100, 18707-18726. https://doi.org/10.1029/95JD02051

[7] Westphal, D.L., Toon, O.B. and Carson, T.N. (1988) A Case Study of Mobilization and Transport of Saharan Dust. Journal of the Atmospheric Sciences, 45, 2145-2175. https://doi.org/10.1175/1520-0469(1988)045<2145:ACSOMA>2.0.CO;2

[8] Gillette, D.A. and Hanson, K.J. (1989) Spatial and Temporal Variability of Dust Production Caused by Wind Erosion in the United States. Journal of Geophysical Research, 94D, 21972206. https://doi.org/10.1029/JD094iD02p02197

[9] Marticorena, B. and Bergametti, G. (1995) Modeling the Atmospheric Dust Cycle, I, Design of Soil-Derived Dust Emission Scheme. Journal of Geophysical Research, 100, 16416-16430. https://doi.org/10.1029/95JD00690

[10] Shao, Y., Raupach, M.R. and Leys, J.F. (1996) A Model for Predicting Aeolian Sand Drift and Dust Entrainment on Scales from Paddock to Region. Australian Journal of Soil Research, 34, 309-342. https://doi.org/10.1071/SR9960309

[11] Marticorena, B., Bergametti, G., Aumont, B., Callot, Y., N’Doume, C. and Legrand, M. (1997) Modeling the Atmospheric Dust Cycle: 2. Simulation of Saharan Dust Sources. Journal of Geophysical Research, 102, 4387-4404. https://doi.org/10.1029/96JD02964

[12] Shao, Y. and Leslie, L.M. (1997) Wind Erosion Prediction over Australian Continent. Journal of Geophysical Research, 102, 30091-30105. https://doi.org/10.1029/97JD02298

[13] Lu, H. and Shao, Y. (2001) Toward Quantitative Prediction of Dust Storms: An Integrated Wind Erosion Modeling System and Its Application. Environmental Modelling \& Software, 16, 233-249. https://doi.org/10.1016/S1364-8152(00)00083-9

[14] Alfaro, S.C. and Gomes, L. (2001) Modeling Mineral Aerosol Production by Wind Erosion: Emission Intensities and Aerosol Size Distributions in Source Areas. Journal of Geophysical Research, 106, 18075-18084.

[15] Song, Z. (2004) A Numerical Simulation of Dust Storms in China. Environmental Modeling 
\& Software, 19, 141-151. https://doi.org/10.1016/S1364-8152(03)00116-6

[16] Gong, S.L. and Zhang, X.Y. (2008) CUACE/Dust-An Integrated System of Observation and Modeling Systems for Operational Dust Forecasting in Asia. Atmospheric Chemistry and Physics, 8, 2333-2340. https://doi.org/10.5194/acp-8-2333-2008

[17] Liu, C., Zhao, T., Xiong, J., et al. (2015) A Simulated Climatology of Dust Aerosol Emissions over 1991-2010 and the Influencing Factors of Atmospheric Circulation over the Major Deserts in the World. Journal of Desert Research, 35, 959-970. (In Chinese)

[18] Gherboudj, I., Beegum, S.N., Marticorena, B. and Ghedira, H. (2015) Dust Emission Parameterization Scheme over the MENA Region: Sensitivity Analysis to Soil Moisture and Soil Texture. Journal of Geophysical Research: Atmospheres, 120. https://doi.org/10.1002/2015jd023338

[19] Wu, C. and Lin, Z. (2013) Uncertainty in Dust Budget over East Asia Simulated by WRF/Chem with Six Different Dust Emission Schemes. Atmospheric and Oceanic Science Letters, 6, 428-433.

[20] Liu, L., Huang, X., Ding, A., et al. (2016) Dust-Induced Radiative Feedbacks in North China: A Dust Storm Episode Modeling Study Using WRF-Chem. Atmospheric Environment, 129, 43-54. https://doi.org/10.1016/j.atmosenv.2016.01.019

[21] Patrick, S. (2008) Application of Aerosol Speciation Data as an in Situ Dust Proxy for Validation of the Dust Regional Atmospheric Model (DREAM). Atmospheric Environment, 42, 7304-7309. https://doi.org/10.1016/j.atmosenv.2008.06.018

[22] Chin, M., Ginoux, P., Kinne, S., Torres, O., Holben, B.N., et al. (2002) Tropospheric Aerosol Optical Thickness from the GOCART Model and Comparisons with Satellite and Sun Photometer Measurements. Journal of the Atmospheric Sciences, 59, 461-483. https://doi.org/10.1175/1520-0469(2002)059<0461:TAOTFT>2.0.CO;2

[23] Niu, T., Gong, S.L., Zhu, G.F., Liu, H.L., Hu, X.Q., Zhou, C.H. and Wang, Y.Q. (2008) Data Assimilation of Dust Aerosol Observations for CUACE/Dust Forecasting System. Atmospheric Chemistry and Physics, 8, 3473-3482. https://doi.org/10.5194/acp-8-3473-2008

[24] Wang, T., Li, S., Shen, F., Deng, J. and Xie, M. (2010) Investigations on Direct and Indirect Effect of Nitrate on Temperature and Precipitation in China Using a Regional Climate Chemistry Modeling System. Journal of Geophysical Research, 115, D00K26. https://doi.org/10.1029/2009JD013165

[25] Wang, T., Li, S., Zhuang, B. and Sheng, F. (2010) Study on the First Indirect Climatic Effect of Sulfate Aerosol in China. Scientia Meteorologica Sinica, 30, 730-740. (In Chinese)

[26] Zhuang, B.L., Liu, L., Shen, F.H., Wang, T.J. and Han, Y. (2010) Semidirect Radiative Forcing of Internal Mixed Black Carbon Cloud Droplet and Its Regional Climatic Effect over China. Journal of Geophysical Research, 115, D00K19. https://doi.org/10.1029/2009JD013165

[27] Li, S., Wang, T., Zhuang, B. and Han, Y. (2009) Indirect Radiative Forcing and Climatic Effect of the Anthropogenic Nitrate Aerosol on Regional Climate of China. Advance in Atmospheric Science, 26, 543-552. https://doi.org/10.1007/s00376-009-0543-9

[28] Deng, J., Cai, Y., Jiang, Z., Wang, T. and Shen, Y. (2011) Characterization of Visibility and Its Affecting Factors in Nanjing, China. Atmospheric Research, 101, 681-691. https://doi.org/10.1016/j.atmosres.2011.04.016

[29] Shen, F., Wang, T., Zhuang, B. and Li, S. (2011) The First Indirect Radiative Forcing of Dust Aerosol and Its Effect on Regional Climate in China. China Environmental Science, 31, 423-430. (In Chinese)

[30] Acker, J.G. and Leptoukh, G. (2007) Online Analysis Enhances Use of NASA Earth Science Data. Eos, Transactions American Geophysical Union, 88, 14-17. https://doi.org/10.1029/2007EO020003 
[31] Sun, X., Zhou, J. and Zhou, Y. (2016) Statistical Characteristics of Aerosol Extinction Coefficient Profile in East Asia from CALIPSO. EPJ Web of Conferences, 119, Article No. 04011.

[32] Tanre, D., Kaufman, Y.J. and Holben, B.N. (2001) Climatology of Dust Aerosol Size Distribution and Optical Properties Derived from Remotely Sensed Data in the Solar Spectrum. Journal of Geophysical Research, 106, 18205-182I7.

[33] Dubovik, O., Holben, B., Eck, T.F., Smirnov, A., Kaufman, Y.J., King, M.D., Tanre, D. and Slutsker, I. (2001) Variability of Absorption and Optical Properties of Key Aerosol Types Observed in Worldwide Locations. Journal of the Atmospheric Sciences, 59, 590-608.

[34] Young, S.A., Vaughan, M.A., Kuehn, R.E., et al. (2013) The Retrieval of Profiles of Particulate Extinction from Cloud-Aerosol Lidar and Infrared Pathfinder Satellite Observations (CALIPSO) Data: Uncertainty and Error Sensitivity Analyses. Journal of Atmospheric and Oceanic Technology, 30, 395-428. https://doi.org/10.1175/JTECH-D-12-00046.1

[35] Friese, C.A., van der Does, M., Merkel, U., et al. (2016) Environmental Factors Controlling the Seasonal Variability in Particle Size Distribution of Modern Saharan Dust Deposited off Cape Blanc. Aeolian Research, 22, 165-179. https://doi.org/10.1016/j.aeolia.2016.04.005

[36] Grini, A., Myhre, G., Zender, C.S., et al. (2005) Model Simulations of Dust Sources and Transport in the Global Atmosphere: Effects of Soil Erodibility and Wind Speed Variability. Journal of Geophysical Research, 110, D02205. https://doi.org/10.1029/2004JD005037

[37] Jiang, F., Wang, T., Wang, T., Xie, M. and Zhao, H. (2008) Numerical Modeling of a Continuous Photochemical Pollution Episode in Hong Kong Using WRF-Chem. Atmospheric Environment, 42, 8717-8727. https://doi.org/10.1016/j.atmosenv.2008.08.034

[38] Laurent, B., Marticorena, B., Bergametti, G. and Mei, F. (2006) Modeling Mineral Dust Emissions from Chinese and Mongolian Deserts. Global and Planetary Change, 52, 121 141. https://doi.org/10.1016/j.gloplacha.2006.02.012

\section{Submit or recommend next manuscript to SCIRP and we will provide best service for you:}

Accepting pre-submission inquiries through Email, Facebook, LinkedIn, Twitter, etc. A wide selection of journals (inclusive of 9 subjects, more than 200 journals)

Providing 24-hour high-quality service

User-friendly online submission system

Fair and swift peer-review system

Efficient typesetting and proofreading procedure

Display of the result of downloads and visits, as well as the number of cited articles

Maximum dissemination of your research work

Submit your manuscript at: http://papersubmission.scirp.org/

Or contact acs@scirp.org 